\title{
Core fluorination enhances solubility and ambient stability of an IDT-based n- type semiconductor in transistor devices
}

Thomas Hodsden, Karl J. Thorley, Julianna Panidi, Aniruddha Basu, Adam V. Marsh, Haojie Dai, Andrew J. P. White, Changsheng Wang, William Mitchell, Florian Glöcklhofer, Thomas D. Anthopoulos*, Martin Heeney*

T. Hodsden, A. V. Marsh, H. Dai, Dr. A. J. P. White, Dr. F. Glöcklhofer, Prof. M. Heeney Department of Chemistry and Centre for Plastic Electronics, White City Campus, Imperial College London, London, W12 0BZ, UK

E-mail: $\underline{\text { m.heeney@imperial.ac.uk }}$

Dr. K. J. Thorley

Department of Chemistry, University of Kentucky, Lexington, KY 40506-0055, USA

J. Panidi

Department of Physics and Centre for Plastic Electronics, South Kensington Campus, Imperial College London, London, SW7 2AZ, UK

Dr. A. Basu, Prof. T. D. Anthopoulos

King Abdullah University of Science and Technology (KAUST), KAUST Solar Center (KSC), Division of Physical Sciences and Engineering, Thuwal 23955-6900, Kingdom of Saudi Arabia E-mail: thomas.anthopoulos@kaust.edu.sa

Dr. C. Wang, Dr. W. Mitchell

Performance Materials Division, Advanced Technologies, Merck Chemicals Ltd., Chilworth Technical Centre, University Parkway, Southampton, SO16 7QD, UK 
Keywords: small molecules, n-type semiconductors, fluorination, organic field-effect transistors, ambient stability

The synthesis of a novel fluorinated n-type small molecule based on an indacenodithiophene core is reported. Fluorination is found to have a significant impact on the physical properties, including a surprisingly dramatic improvement in solubility, in addition to effectively stabilizing the LUMO energy $(-4.24 \mathrm{eV})$. Single crystal analysis and DFT calculations indicate the improved solubility can be attributed to backbone torsion resulting from the positioning of the fluorine group in close proximity to the strongly electron-withdrawing dicyanomethylene group. Organic thin-film transistors made via blade coating display high electron mobility (up to $0.49 \mathrm{~cm}^{2} \mathrm{~V}^{-1} \mathrm{~s}^{-1}$ ) along with good retention of performance in ambient conditions.

\section{Introduction}

Organic semiconductors (OSCs) have attracted much attention for use in optoelectronic applications owing to the potential for flexible, lightweight devices where performance can be fine-tuned by means of chemical and processing modifications. In particular, solution-processable OSCs find application in a number of emerging fields including organic field-effect transistors (OFETs), organic thermoelectrics, electrochemical transistors, spintronics and energy storage systems, to name a few. ${ }^{[1,2]}$ OSCs designed for OFET applications require $\pi$-conjugated backbones as well as close intermolecular $\pi-\pi$ stacking interactions to facilitate efficient charge transport by maximization of orbital overlap. One attractive approach towards such materials has been the fusion of aromatic moieties into rigid, ladder-type systems. ${ }^{[3]}$ The high rigidity minimizes reorganization energy by reduction of torsional disorder, as well improving intra- and intermolecular charge delocalization. However, such modifications inherently reduce processability, meaning careful selection of the nature and position of suitable alkyl chains needs to be considered to facilitate solution-processability while maintaining favourable charge transport properties. ${ }^{[4]}$ 
Amongst the various reported ladder-type systems, OSCs incorporating the 4,9-dihydro-sindaceno[1,2-b:5,6-b']dithiophene (IDT) unit have demonstrated particular promise. ${ }^{[5-7]}$ Such performance has been related to the fused, highly rigid nature of the IDT core and good processability by facile alkylation at the bridging points. The terminal thienyl group also helps to reduce torsional twisting with adjacent co-monomers, facilitating backbone planarization. ${ }^{[8]}$ For example, donoracceptor polymers utilizing the 4,4,9,9-tetraalkyl-4,9-dihydro-s-indaceno[1,2-b:5,6-b']dithiophene as the donor have been reported with hole mobilities up to $3.6 \mathrm{~cm}^{2} \mathrm{~V}^{-1} \mathrm{~s}^{-1},{ }^{[5,9]}$ while polymers based on the $\pi$-extended indacenodithieno[3,2-b]thiophene (IDTT) exhibited hole mobilities up to $8.7 \mathrm{~cm}^{2} \mathrm{~V}^{-}$ ${ }^{1} \mathrm{~S}^{-1} \cdot[10]$

While the majority of high-performance OFETs are comprised of p-type OSCs, n-type OSCs are far less numerous. ${ }^{[1,12]}$ New n-type OSCs are eagerly sought for use in devices such as complementary circuits and organic photovoltaics, where balanced charge transport between the n-type and p-type components is crucial. ${ }^{[13-16]}$ OSCs for n-type applications require a low-lying lowest-unoccupied molecular orbital (LUMO) to enable good charge injection from the metal electrode and to improve ambient stability of the reduced species. ${ }^{[17-19]}$ A figure of $-4 \mathrm{eV}$ or lower is often quoted, but it worth noting that OSC energetics alone do not guarantee operational stability of the overall device. ${ }^{[17]}$ Depression of the LUMO energy is typically achieved by the incorporation of strongly electronwithdrawing groups (EWGs), such as carbonyl, imide and cyano moieties, which are able to lower the LUMO due to their favourable electron-accepting properties. ${ }^{[20]}$ Halogenation, in particular fluorination, has been widely explored in the literature as another tool to tune the properties of OSCs. ${ }^{[21,22]}$ The introduction of strongly electronegative fluorine groups has been shown to be an effective strategy for stabilizing the LUMO levels. ${ }^{[23-26]}$ Owing to the small van der Waals radius, fluorination is highly attractive as these benefits can usually be achieved without disruption to backbone planarity from the introduction of undesired steric clashes. In addition, fluorination often helps to promote inter- and intramolecular interactions via a range of non-covalent interactions. ${ }^{\text {[27-30] }}$ 
However these enhanced interactions often result in a detrimental reduction in solubility in comparison to the non-fluorinated analogue, leading to processability challenges.

Based on the high performance of IDT as a p-type OSC, there have been attempts to modify the core for use in n-type applications. The inherently electron-rich nature of IDT results in a high lying LUMO making it a poor candidate for n-type transport. This can be improved however by the introduction of strong EWGs which act to depress the LUMO. Introduction of EWGs at the terminal thienyl units (Figure 1a) have been explored in acceptor-donor-acceptor (A-D-A) non-fullerene acceptors (NFAs) for use in organic solar cells. ${ }^{[31,32]}$ Several reports have also shown that these IDTbased NFAs display promising performance in thin-film transistor applications. ${ }^{[33,34]}$ Alternative attempts have focussed upon chemically modifying the core via the introduction of strong EWGs at the 4,9-bridging positions of the IDT backbone (Figure 1b). Based on initial work by Zhao et al., Tian et al. and more recently Peltier et al. have investigated carbonyl bridge IDTs (IDT-di(O)), for use in OFETs. ${ }^{[35-37]}$ It has been reported that vacuum-processed devices of 2,7-dihexyl-sindaceno[1,2-b5,6-b']dithiophene-4,9-dimalononitrile (IDT-di(C(CN)2)) exhibited unipolar electron mobility up to $0.33 \mathrm{~cm}^{2} \mathrm{~V}^{-1} \mathrm{~s}^{-1}$. With the bridging positions occupied by the EWGs, hexyl solubilizing chains were placed at the terminal thienyl units instead. A low density of alkyl chains ( 2 alkyl chains per molecule) coupled with an in-plane configuration (owing to positioning of the alkyl chains at a $\mathrm{sp}^{2} \mathrm{C}$ ) led to the material being poorly soluble in common organic solvents. This is in contrast to the highly soluble IDT materials with alkylation at the bridging point (4 alkyl chains per molecule, $\mathrm{sp}^{3}$ C, out-of-plane) (Figure 1a). As a result, IDT-di(C(CN)2) was unsuitable for device processing from solution. Solution processing is highly desired due to the low processing temperatures and high scalability compared to vacuum processing.

In this work, we examine for the first time fluorination of the central IDT core (Figure 1c) as a route to improve ambient stability. Surprisingly we find that core fluorination results in improved solubility and processability over the non-fluorinated analogues, enabling the fabrication of solution-processed OFET devices exhibiting high unipolar electron mobility (up to $0.49 \mathrm{~cm}^{2} \mathrm{~V}^{-1} \mathrm{~s}^{-1}$ ) with promising 4 
ambient stability. The improved solubility is in contrast to most reports of semiconductor fluorination which result in significantly reduced solubility. By examination of the single crystal packing motifs with density functional theory (DFT) we demonstrate that this is due to the larger fluorine groups inducing significant steric hindrance in this molecule, leading to disruption from planarity of the $\pi$ conjugated system.

\section{Results and Discussion}

\subsection{Design and Synthesis}

2,7-Dihexyl-5,10-difluoro-s-indaceno[1,2-b5,6-b']dithiophene-4,9-dimalononitrile

(diFIDT$\left.\operatorname{di}\left(\mathbf{C}(\mathbf{C N})_{2}\right)\right)$ was synthesized following a route modified from the reported synthesis of the nonfluorinated analogue, IDT-di(C(CN)2) (Scheme 1). ${ }^{[36,37]}$ The critical step was the formation of the hexa-substituted benzene derivative, diethyl 2,5-dibromo-3,6-difluoroterephthalate ([2]). After some experimentation it was found that 1,4-dibromo-2,5-difluorobenzene ([1]) could be doubly deprotonated by the Knochel-Hauser base, 2,2,6,6-tetramethylpiperidinylmagnesium chloride lithium chloride, at $-40^{\circ} \mathrm{C}$. Subsequent reaction with ethyl chloroformate afforded the desired product in 30 $\%$ yield. ${ }^{[38,39]}$ The bromo substituents were subsequently utilized in a Stille cross-coupling with trimethyl(5-hexylthiophen-2-yl)stannane ([3]) using tetrakis(triphenylphosphine)palladium(0) to afford diethyl 2,5-difluoro-3,6-bis(5-hexylthiophen-2-yl)terephthalate in high yield ([4]) (83\%) after purification by silica gel chromatography. Saponification with $\mathrm{KOH}$ in ethanol afforded a quantitative conversion to the diacid ([5]), which was converted to the acid chloride by treatment with $\mathrm{SOCl}_{2}$ in DCM in the presence of a catalytic amount of DMF. After solvent removal, the resulting watersensitive material was used directly without purification.

Ring closure was achieved by a Lewis acid-promoted intramolecular Friedel-crafts acylation with $\mathrm{AlCl}_{3}$ to afford the diketone, 2,7-dihexyl-5,10-difluoro-s-indaceno[1,2-b:5,6-b']dithiophene-4,9dione, diFIDT-di(O) (80\%). DiFIDT-di(O) was soluble in common organic solvents (such as chloroform, DCM and THF). Knoevenagel condensation of the diketone with malononitrile and 
pyridine at room temperature gave the title compound, 2,2'-(5,10-difluoro-2,7-dihexyl-sindaceno[1,2-b:5,6-b']dithiophene-4,9-diylidene)dimalononitrile, $\quad \operatorname{diFIDT-di(C(CN)2)}(80 \quad \%)$.

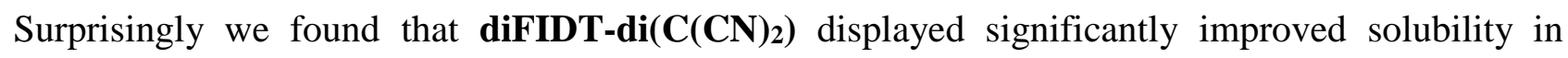
organic solvents (such as chloroform and THF) compared to the previously reported non-fluorinated analogue, despite the higher molecular weight of the former. This is strikingly in contrast to most reports of fluorinated organic semiconductors, in which solubility and processability is significantly lower than their non-fluorinated analogues. ${ }^{[40-42]}$ The improved solubility facilitated purification via liquid phase extraction and reprecipitation. Solubility tests revealed that $\operatorname{diFIDT}-\mathbf{d i}(\mathbf{C}(\mathbf{C N}) \mathbf{2})$ (4 $\mathrm{mg} / \mathrm{mL})$ was more than 20 times as soluble as IDT-di(C(CN)2 $)(<0.2 \mathrm{mg} / \mathrm{mL})$ in chlorobenzene at $25^{\circ} \mathrm{C}$ (procedure outlined in the Experimental section). Notably, the solubility of $\operatorname{diFIDT}-\mathbf{d i}\left(\mathbf{C}(\mathbf{C N})_{2}\right)$ increased to $>10 \mathrm{mg} / \mathrm{mL}$ in chlorobenzene with gentle heating $\left(50^{\circ} \mathrm{C}\right)$, indicating suitability of this OSC for solution-processing (vide infra).

The chemical structures of $\operatorname{diFIDT}-\operatorname{di}(\mathbf{O})$ and $\operatorname{diFIDT}-\operatorname{di}\left(\mathbf{C}(\mathbf{C N})_{2}\right)$ were verified by ${ }^{1} \mathrm{H} \mathrm{NMR},{ }^{19} \mathrm{~F}$ NMR, ${ }^{13} \mathrm{C}$ NMR, IR, HRMS and XRD. In order to enable a direct comparison of physical and electrochemical properties, the non-fluorinated analogues IDT-di(O) and IDT-di(C(CN)2) were synthesized in accordance with the literature procedures.

\subsection{Molecular Organization}

Molecular modelling was performed using DFT with a B3LYP level of theory using the 6-311+G(d,p) basis set, as also employed by Peltier et al. ${ }^{[37]} \operatorname{DiFIDT-di(O)}$ and $\left.\left.\operatorname{diFIDT-di(C(CN)}\right)_{2}\right)$ were predicted to have LUMO/HOMO energies of $-3.55 /-6.07 \mathrm{eV}$ and $-4.47 /-6.40 \mathrm{eV}$ respectively. These values corresponded to a depression in both the HOMO and LUMO levels from the introduction of fluorine groups, by $0.23 / 0.29 \mathrm{eV}$ and $0.16 / 0.23 \mathrm{eV}$ respectively, resulting in a small decrease in the band gap. As with the non-fluorinated analogues, the HOMO of both $\operatorname{diFIDT-di(O)}$ and $\operatorname{diFIDT}-\operatorname{di}\left(\mathbf{C}(\mathbf{C N})_{2}\right)$ were shown to be delocalized across the IDT core, whereas the LUMO was localized on the bridging point (Figure S16). While the diketone compounds and IDT-di $\left(\mathbf{C}(\mathbf{C N})_{2}\right)$ possess planar geometries, 


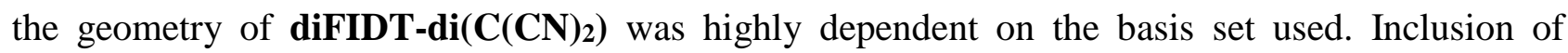
additional diffuse functions favoured a non-planar geometry, while smaller basis sets favoured a planar geometry. This difficulty in finding energetic minima suggests a low energetic barrier for conversion between planar and non-planar geometries. This observation may help to explain the increased solubility of the $\operatorname{diFIDT}-\operatorname{di}\left(\mathbf{C}(\mathbf{C N})_{2}\right)$, since a less planar and more flexible core would increase the entropic contribution to the free energy of solvation.

Single crystals were grown via the solvent vapour exchange method using either chloroform/methanol (diFIDT-di(O)) or chlorobenzene/methanol (diFIDT-di(C(CN)2)) mixtures. The crystal structures for IDT-di(O) and IDT-di(C(CN)2) were downloaded from the Cambridge Crystallographic Data Centre for comparison. DiFIDT-di(O) crystallized in the triclinic space group $P-1$. The IDT core was completely coplanar, in agreement with the DFT calculation (See Supplementary Information for full description). The hexyl chains on the thienyl $\alpha$-position lie outside the plane with a dihedral angle of $52^{\circ}$. A planar slipped $\pi$ - $\pi$ stacking arrangement is formed along the $a$ axis with partial alkyl chain interdigitation (Figure 2a \& 2c). There is co-facial packing of the conjugated core within a stack, along the $a$ axis, with an interplanar stacking distance of $3.49 \AA$ and a slipping distance of $4.34 \AA$ (angle $51.0^{\circ}$ ) (Figure S19b). These values are larger than for IDT-di(O) (interplanar stacking distance of $3.26 \AA$, slipping distance of $3.95 \AA$ ). Specific short contacts are

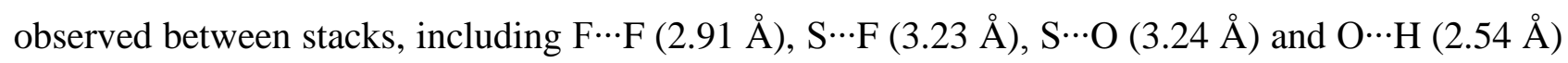
interactions as well as intramolecular O $\cdots \mathrm{F}(3.06 \AA$ ) interactions (Figure 2b).

The presence of short contacts, particularly like the $\mathrm{S} \cdots \mathrm{F}$ and $\mathrm{S} \cdots \mathrm{O}$ interactions observed for diFIDT$\operatorname{di}(\mathbf{O})$, is often assumed to be stabilizing and therefore desirable for enabling efficient charge transport through stacks. However, recent work has highlighted that the overall effect is highly dependent on the balance between repulsive (exchange) and attractive (induction, electrostatic and dispersion) interactions. ${ }^{[27,43]}$ To gain insight into the intermolecular interaction energies, symmetry adapted perturbation theory (SAPT0/jun-cc-pvdz) calculations were performed. SAPT0 analysis allows the total interaction energies between molecular pairs extracted from the crystal structures to be 
decomposed into the respective non-covalent interactions. Analysis was performed on molecular pairs of IDT-di(O) and diFIDT-di(O) from their respective crystal packing motifs. In addition, the IDT-di(O) molecules in their crystal packing were altered by substitution of the central protons for fluorine atoms, thus leading to the hypothetical diFIDT-di(O) molecules in the IDT-di(O) packing. Similarly, IDT-di(O) molecules were placed in the diFIDT-di(O) packing by replacement of the fluorine atoms for protons. This cross analysis allowed the calculation of the intermolecular interaction energies in both crystal packings, with either central $\mathrm{H}$ or $\mathrm{F}$ groups present. Hence, the molecular origin for the change in crystal packing upon fluorination could be isolated.

The SAPT0 analysis shows that many of the intermolecular contacts in the diFIDT-di(O) crystal packing motif are similar, irrespective of $\mathrm{H}$ or F substitution (See Supplementary Information for full SAPT0 analysis). Surprisingly the interactions between close heteroatoms identified in Figure $\mathbf{2 b}$ afforded little difference in total interaction energy, partly as the increase in stabilizing dispersion and electrostatic energies are offset by increased steric exchange repulsion. One example of this is shown in Figure 3a, where the in-plane longitudinal interaction in the $\operatorname{diFIDT-di(O)}$ crystal packing is almost identical irrespective of $\mathrm{H}$ or $\mathrm{F}$ substitution. The largest stabilization $(2.4 \mathrm{kcal} / \mathrm{mol})$ by introduction of fluorine appears in an edge $\pi$-stacked interaction (Figure $3 \mathbf{b}$ ). This difference is mostly down to an increase in electrostatic stabilization by $2.8 \mathrm{kcal} / \mathrm{mol}$. Another difference between these two molecular alignments is that the $\mathrm{C} \cdots \mathrm{F}$ bond dipoles directly oppose each other in the inplane interaction, reducing the gain in electrostatic stabilization from $\mathrm{S} \cdots \mathrm{F}$ interaction, while the vertical offset of the edge $\pi$-stacked pair means the dipoles can form an anti-parallel stacked stabilizing alignment. These results highlight the caution needed in interpreting the impact of close intermolecular contacts.

DiFIDT-di(C(CN) $)$ crystallized in the monoclinic space group $P 2_{1} / n$, with a planar IDT core and the fluorine groups in this plane. The hexyl chains on the thienyl $\alpha$-position lie outside the plane, with a larger dihedral angle of $82^{\circ}$, similar to that seen for the non-fluorinated analogue. Additionally, there is a slight bowing of the dicyanomethylene groups away from the IDT core plane $\left(7.5^{\circ}\right)$, as 
predicted by DFT calculations, with the two dicyanomethylene groups being positioned on opposite sides of the IDT core plane in a 'trans'-like conformation (Figure 4b). This bowing is greater than that observed for the non-fluorinated analogue $\left(1.5^{\circ}\right)$. This, in addition to a slightly increased $\mathbf{C}=\mathbf{C}$ $\mathbf{C} \equiv \mathrm{N}$ angle $\left(126.7^{\circ}\right.$ vs $\left.124.5^{\circ}\right)$, indicates a weakly repulsive effect from the presence of the $\mathrm{F}$ group, most likely due to its larger van der Waals radius compared to hydrogen (1.47 $\AA$ versus $1.09 \AA$ ). There also appears to be a F ‥ CN non-covalent interaction $(\mathrm{F} \cdots \mathrm{C}(2.69 \AA)$ and $\mathrm{F} \cdots \mathrm{N}(2.84 \AA))($ Figure 4a).

More noticeably, a tilted slipped $\pi-\pi$ stacking arrangement is shown for $\operatorname{diFIDT-di(C(CN)})$, as opposed to the planar slipped $\pi-\pi$ stacking arrangement observed for IDT-di(C(CN)2). This indicates a dramatic change in solid state packing due to the introduction of the F groups. There are alternating aliphatic and conjugated core layers along the $c$ axis and the alkyl chains are interdigitated with each other. There is good co-facial packing of the conjugated core within a stack, with interplanar stacking distance $3.43 \AA$ and slipping distance $2.37 \AA$ (angle $41.8^{\circ}$ ). A slight decrease in stacking distance versus diFIDT-di(O) (3.49 $\AA$ ) and IDT-diC(C(CN)2) (3.47 $\AA$ ) is unexpected considering the slight bowing of the dicyanomethylene groups out of plane, however it may indicate more favourable intermolecular overlap from positioning of the $\delta$ - F groups directly above the $\delta+\mathbf{C}=\mathbf{C}(\mathrm{CN})_{2}$ on neighbouring units in the stack.

A key factor affecting transport through organic crystals is the electronic coupling between neighbouring units, often called the transfer integral. A larger value indicates better overlap between frontier molecular orbitals on neighbouring units (LUMO-LUMO in the case of electron transport) and therefore the potential for more efficient charge transfer. Both IDT-di(C(CN)2) and diFIDT$\operatorname{di}\left(\mathbf{C}(\mathbf{C N})_{2}\right)$ single crystals display one-dimensional (1D) charge transfer pathways, with calculated electron transfer integrals (B3LYP/6-31G(d)) of $97 \mathrm{meV}$ and $129 \mathrm{meV}$ respectively for the main $\pi$ stacks. Other close contacts resulted in low transfer integrals of $<10 \mathrm{meV}$ (Figure S24). While 1D packing can result in lower charge mobility than multidimensional structures, the transfer integrals 
obtained here are amongst the highest for small molecule organic semiconductors and may help to explain the good transistor performance (vide infra). ${ }^{[44-46]}$

Once again, SAPT0 analysis was used to distinguish between the packing configurations, placing both fluorinated and non-fluorinated molecules into each crystal structure (see Supplementary Information for full analysis). In the case of the $\left.\operatorname{diFIDT-di(} \mathbf{C}(\mathbf{C N})_{2}\right)$ packing, the substitution of $\mathrm{F}$ with $\mathrm{H}$ makes very little difference to pairwise interaction energies. This can be seen by the location of the fluorine substituent (Figure 5a), where it has no in-plane intermolecular short contacts and thus has little influence. The main difference in the IDT-di(C(CN)2) packing originates from the inplane edge-to-edge interaction, between adjacent molecules (Figure 5b). The non-fluorinated derivative results in an interaction stabilization $11.8 \mathrm{kcal} / \mathrm{mol}$ stronger than the fluorinated one. This difference is the result of a large steric repulsion by the inclusion of fluorine, which is simply too

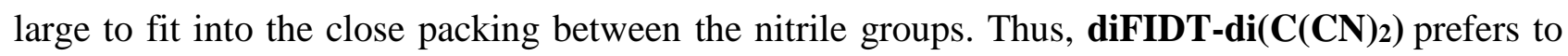
adopt the crystal packing where steric repulsion from fluorine groups is minimized.

Introduction of EWGs to polycyclic aromatics usually reduces the exchange repulsion while keeping similar dispersion stabilization, promoting $\pi$-stacking. A surprising finding from all the SAPT0 analysis is that the inclusion of fluorine does not strengthen the $\pi$-stacking interactions. The presence of strong electron-deficient carbonyl or nitrile groups in close proximity to the central phenyl could explain why the addition of fluorine does not significantly improve the $\pi$-stacking stabilization. The other main conclusion is that inclusion of fluorine does not necessarily introduce more favourable non-covalent interactions with other heteroatoms (e.g. sulfur) simply because the two atoms are close in space. The close contact is accompanied by increased steric repulsion such that the overall intermolecular interaction energy is no different to if there were just a hydrogen substituent, and in some cases making the interaction less stable.

\subsection{Electrochemical Properties}


Electrochemical studies of $\operatorname{diFIDT-di(O)}$ and $\operatorname{diFIDT-di(}\left(\mathbf{C}(\mathbf{C N})_{2}\right)$ were performed by cyclic voltammetry $(\mathrm{CV})$ using a $0.1 \mathrm{M}$ solution of $\mathrm{Bu}_{4} \mathrm{NPF}_{6}$ in $\mathrm{DCM}$ solutions and a ferrocene $\left(\mathrm{Fc}^{+} / \mathrm{Fc}\right)$ internal standard. In line with best practice, energy levels were estimated from $E^{1 / 2}$ (when reversibility is observed) or $E^{i}$ (when irreversibility is observed), where $E^{1 / 2}$ is the half-wave potential, $E^{i}$ is the inflection-point potential. ${ }^{[47]} \mathrm{HOMO}=-\left(E^{1 / 2 \text { or } i}+4.8\right) \mathrm{eV}$ and $\mathrm{LUMO}=-\left(E^{1 / 2 \text { or } i}+4.8\right) \mathrm{eV}$ for oxidation and reduction respectively, with the ferrocene/ferrocenium reference redox system at 4.8 eV below the vacuum level. Electrochemical data for IDT-di(O), was reanalysed by the method above to ensure a reliable comparison. $E^{1 / 2}$ and $E^{i}$ values for IDT-di(C(CN)2) were estimated from the literature data due to poor solubility.

Both diFIDT-di(O) and diFIDT-di(C(CN)2) exhibit multiple reversible reduction peaks with $E^{1 / 2}$ located at $-1.04 \mathrm{~V} /-1.53 \mathrm{~V}$ and $-0.56 \mathrm{~V} /-0.95 \mathrm{~V} /-2.19 \mathrm{~V}$ respectively (Figure 6a). This corresponds to estimated LUMO levels of $-3.76 \mathrm{eV}$ and $-4.24 \mathrm{eV}$ respectively (Table 1). For comparison, use of $E^{e}$ (edge potential) instead of $E^{1 / 2}$ estimated LUMO levels $\sim 0.1 \mathrm{eV}$ lower $(-3.85 \mathrm{eV}$ and $-4.35 \mathrm{eV})$. This systematic overestimation of LUMO level for small molecule OSCs is an important factor to consider for n-type applications, where energy alignment with the electrodes and thermodynamic stability are crucial. A large depression in the LUMO level $(0.48 \mathrm{eV})$ of $\operatorname{diFIDT}-\operatorname{di}\left(\mathbf{C}(\mathbf{C N})_{2}\right)$ versus diFIDT-di(O) reflects how the introduction of the strongly electron-withdrawing dicyanomethylene group can act to effectively stabilize the reduced state. A low-lying LUMO indicated potential ambient stability for $\operatorname{diFIDT-di(}\left(\mathbf{C}(\mathbf{C N})_{2}\right)$ as well as good energy alignment with electrodes for charge injection in OFET devices. As predicted by DFT, the introduction of highly electronegative F groups caused a stabilization of the LUMO level by $0.2-0.3 \mathrm{eV}$ for $\operatorname{diFIDT-di(O)}$ and $\left.\operatorname{diFIDT-di(C(CN)})_{2}\right)$ versus the non-fluorinated analogues (-3.43 eV and $-4.02 \mathrm{eV}$ respectively) (Figure 6b and Table 1).

Unlike the reduction peaks, $\operatorname{diFIDT-di(O)}$ and $\operatorname{diFIDT-di(C(CN)2)}$ showed weakly reversible/irreversible oxidation peaks with $E^{i}$ located at $1.14 \mathrm{~V}$ and $1.20 \mathrm{~V}$ respectively, corresponding to estimated HOMO levels of $-5.94 \mathrm{eV}$ and $-6.00 \mathrm{eV}$. A significant depression of the LUMO without a corresponding effect on the HOMO, as observed here, results in a large decrease in 11 
electrochemical gap, from $2.20 \mathrm{eV}$ to $1.76 \mathrm{eV}$. This effect is explained by the highly localized nature of the LUMO at the bridge point, allowing selective tuning of the LUMO level by choice of functionality at this position, as previously observed. ${ }^{[37]}$ The introduction of $\mathrm{F}$ groups was seen to decrease the HOMO level by $0.1 \mathrm{eV}$ and $0.36 \mathrm{eV}$ versus IDT-di(O) and IDT-di(C(CN)2) respectively $(-5.84 \mathrm{eV} \&-5.64 \mathrm{eV})$

\subsection{UV-Vis Absorption Spectra}

The absorption spectra for $\operatorname{diFIDT-di(O)}$ and $\operatorname{diFIDT-di}\left(\mathbf{C}(\mathbf{C N})_{2}\right)$ in solution (toluene and chloroform, $10^{-5} \mathrm{M}$ ) are shown in Figure $6 \mathbf{c} \& \mathbf{6 d}$ and summarised in Table 1. As with the nonfluorinated analogues, both compounds displayed strong well-defined absorption bands at shorter wavelengths (250-450 $\mathrm{nm})$ as well as broad weak absorption at longer wavelengths (450-750 $\mathrm{nm}$ and 550-1050 nm respectively). From the onset of absorption at the longer wavelengths, optical gaps of $1.65 \mathrm{eV}$ and $1.21 \mathrm{eV}$ are observed for $\operatorname{diFIDT}-\mathbf{d i}(\mathbf{O})$ and $\operatorname{diFIDT}-\mathbf{d i}\left(\mathbf{C}(\mathbf{C N})_{2}\right)$ respectively. Timedependent DFT (TD-DFT) indicated that the very weak oscillator strength of this transition $(f=0.074$ and 0.048 respectively) arises due to the absence of significant overlap between the HOMO, located on the IDT core, and the LUMO, located on the cyclopentadienyl-dicyanomethylene bridging unit (Figure S17). Optical gaps were slightly reduced versus IDT-di(O) and IDT-di(C(CN)2) $(1.84 \mathrm{eV}$ and $1.29 \mathrm{eV}$ respectively).

\subsection{Thermal Properties}

The thermal behaviour of $\operatorname{diFIDT-di}(\mathbf{O})$ and $\operatorname{diFIDT-di}\left(\mathbf{C}(\mathbf{C N})_{2}\right)$ was investigated by thermal gravimetric analysis (TGA) (Figure S27) and differential scanning calorimetry (DSC) (Figure S28)

and are summarised in Table 1. Both compounds exhibit high thermal stability, with the onset of decomposition occurring at $>310^{\circ} \mathrm{C}$, as with the non-fluorinated analogues. There is a large decrease in $T_{d}$ (temperature at which 5\% mass loss is reached) from diFIDT-di(O) to $\operatorname{diFIDT-di(C(CN)2)}\left(T_{d}\right.$ $=360^{\circ} \mathrm{C}$ versus $\left.T_{d}=319^{\circ} \mathrm{C}\right)$. Moreover, while $\mathbf{d i F I D T}-\mathbf{d i}(\mathbf{O})$ shows improved thermal stability compared to the non-fluorinated analogue $\left(T_{d}=331^{\circ} \mathrm{C}\right)$, the opposite is observed for diFIDT- 
$\operatorname{di}\left(\mathbf{C}(\mathbf{C N})_{2}\right)($ IDT-di(C(CN)2 $\left.) T_{d}=349^{\circ} \mathrm{C}\right)$. DiFIDT-di(O) melts at $221^{\circ} \mathrm{C}\left(\Delta H_{m}=83 \mathrm{Jg}^{-1}\right)$, which is more than $50^{\circ} \mathrm{C}$ above that reported for IDT-di(O) $\left(172^{\circ} \mathrm{C}\right)$. This compound is also stable in the liquid state up to the maximum temperature used in this experiment $\left(250^{\circ} \mathrm{C}\right)$, with no changes observed upon repeated thermal cycling. In contrast, $\left.\operatorname{diFIDT-di(} \mathbf{C}(\mathbf{C N})_{2}\right)$ displays degradation upon melting at $248^{\circ} \mathrm{C}\left(\triangle H_{m}=59 \mathrm{Jg}^{-1}\right)$, evidenced by a gradual shift and reduction in melting/crystallizing endo/exotherms upon repeated thermal cycling. An increase in melting temperature $\left(T_{m}\right)$ from diFIDT$\operatorname{di}(\mathbf{O})$ to $\operatorname{diFIDT}-\operatorname{di}\left(\mathbf{C}(\mathbf{C N})_{2}\right)$ is in line with that seen for the non-fluorinated analogues, highlighting stronger intermolecular $\pi-\pi$ stacking interactions. However, it is surprising that the liquid state of

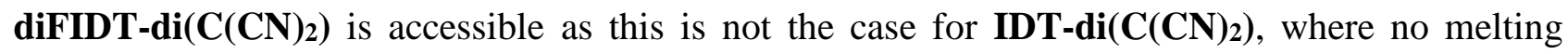
endotherm is observed up to $300^{\circ} \mathrm{C}$.

Fluorination of the central phenyl ring is thus shown to have differing effects on the thermal properties, depending on the bridging electron-withdrawing group present. For diFIDT-di(O), the relative increase in thermal stability and melting point suggests stronger intermolecular interactions in the solid state. For diFIDT-di(C(CN)2) however, the presence of fluorine groups appears to disrupt aggregation, resulting in a lower thermal stability and melting point (and increased solubility). These observations correlate well with the XRD and DFT analysis, particularly for $\operatorname{diFIDT}-\operatorname{di}\left(\mathbf{C}(\mathbf{C N})_{2}\right)$ where the non-planarity imposed by steric repulsion from the fluorine groups appears to noticeably disrupt aggregation in the solid state.

\subsection{Organic Field-Effect Transistors}

The solubility of $\mathbf{d i F I D T}-\operatorname{di}\left(\mathbf{C}(\mathbf{C N})_{2}\right)$ was improved to such an extent as to allow device fabrication via solution-processing of the semiconductor layer. Previous reports using the non-fluorinated IDT$\operatorname{di}\left(\mathbf{C}(\mathbf{C N})_{2}\right)$ quote a distinct lack of solubility in common organic solvents at room temperature. Tian et al. report that the highest performance for IDT-di(C(CN)2) devices using vacuum-deposition, with a saturated mobility up to $0.33 \mathrm{~cm}^{2} \mathrm{~V}^{-1} \mathrm{~s}^{-1}$ after extensive device structure engineering. Far inferior 
performance was achieved via drop-casting, which was only possible from hot 1,2-dichlorobenzene at low concentration $(2 \mathrm{mg} / \mathrm{mL})$, and gave mobilities on the order of $10^{-4} \mathrm{~cm}^{2} \mathrm{~V}^{-1} \mathrm{~s}^{-1} \cdot{ }^{[36]}$

In the first instance, organic thin film transistors (OTFTs) for $\operatorname{diFIDT-di(C(CN)} 2)$ were fabricated in bottom-contact top-gate (BC-TG) configuration (Figure 7a) via spin-coating of the organic semiconductor. Gold source-drain electrodes of $40 \mathrm{~nm}$ were deposited via thermal evaporation in high vacuum, while the organic semiconductor small molecule was spin coated from hot chlorobenzene followed by deposition of CYTOP dielectric and thermal evaporation of the aluminum gate electrode. The primary parameters of devices performance, including mobility $(\mu)$, threshold voltage $\left(V_{T}\right)$ and on-off ratio $\left(I_{o n} / I_{o f f}\right)$ were extracted from both the linear and saturated regimes for devices annealed at $100^{\circ} \mathrm{C}, 150^{\circ} \mathrm{C}$ and $200^{\circ} \mathrm{C}$ (Table S1 and Figure S27). All measurements were recorded in a glovebox under a nitrogen atmosphere.

Devices with diFIDT-di(C(CN)2) exhibited unipolar electron transport. This reflects the role of the deep LUMO level in allowing stable electron transport (Figure 7b). Also, a deep HOMO energy ($6.00 \mathrm{eV}$ ) imparts a large energy level offset with the S/D electrode helping to suppress competing hole injection and possible ambipolar behavior. The best performance was obtained for devices annealed at $100^{\circ} \mathrm{C}$, with an average saturated electron mobility of $0.33 \mathrm{~cm}^{2} \mathrm{~V}^{-1} \mathrm{~s}^{-1}$ with a $V_{T}$ of $8.16 \mathrm{~V}$ and $I_{o n} / I_{\text {off }}$ of $10^{2}$ across 7 devices (Table 2). Increasing annealing temperature results in a slight reduction in performance (Table S1). This mobility is three orders of magnitude higher than that observed for solution-processed devices based on IDT-di(C(CN) $)\left(10^{-4} \mathrm{~cm}^{2} \mathrm{~V}^{-1} \mathrm{~s}^{-1}\right)$ and comparable to the mobility reported when using vacuum-deposited films. A comparable device performance by solution-processing is highly promising. Impressively low $V_{T}$ indicated the presence of minimal charge injection barriers between the S/D electrodes and OSC, suggesting good energy alignment for efficient charge injection as well as good interface morphology. This is also reflected in the similar linear and saturated mobilities found in this geometry (Table 2), suggesting minimal device nonidealities. 
The promising performance observed with spin-coating prompted us to investigate the performance in blade-coated devices. Blade-coating is seen as an attractive solution-processing technique due to better scalability and potential for roll-to-roll processing for industrial production. ${ }^{[48]} \mathrm{Al} / \mathrm{Au}$ sourcedrain electrodes $(5 \mathrm{~nm} / 35 \mathrm{~nm}$ ) were deposited via thermal evaporation in high vacuum. The diFIDT$\operatorname{di}\left(\mathbf{C}(\mathbf{C N})_{2}\right)$ solution $\left(5 \mathrm{mg} / \mathrm{ml}\right.$ in chlorobenzene) was blade coated on the substrates at $100^{\circ} \mathrm{C}$ with a blade speed of $50 \mathrm{~mm} / \mathrm{s}$, and the substrates were kept at $100^{\circ} \mathrm{C}$ for $5 \mathrm{mins}$. This was followed by deposition of CYTOP dielectric and thermal evaporation of the aluminum gate electrode. Figure S30 show the transfer characteristics of OTFTs fabricated using identical processing conditions. Figure S30a displays representative curves for a transistor with low threshold voltage $(-0.91 \mathrm{~V})$ and a reasonably high saturated electron mobility $\left(0.39 \mathrm{~cm}^{2} \mathrm{~V}^{-1} \mathrm{~s}^{-1}\right)$, while Figure S30b shows representative curves for an OTFT with the highest saturated electron mobility $\left(0.49 \mathrm{~cm}^{2} \mathrm{~V}^{-1} \mathrm{~s}^{-1}\right)$ both prepared via blade coating. Figure S31 shows the statistical distribution of the electron mobility (average 0.34 $\mathrm{cm}^{2} \mathrm{~V}^{-1} \mathrm{~s}^{-1}$ ) and threshold voltage extracted from 18 blade-coated OFET devices fabricated simultaneously. The large variations in the threshold voltage suggests the presence of interfacial traps and a strong relation to the local processing conditions. Such issues may explain why the difference between the mobility values extracted in linear and saturation regimes for these blade-coated devices is large. Despite these issues, reliable extraction of saturated electron mobilities was indicated by the absence of double-slopes as well as gate voltage $\left(V_{G}\right)$-independent mobility above the threshold voltage (Figure S30a and Figure S30b).

Tian et al. observed a rapid decrease in performance of vacuum-processed IDT-di(C(CN)2) devices in air. However, improved thin film morphology via surface modification greatly improved stability.

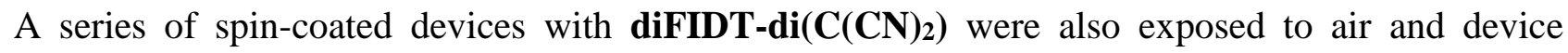
performance (in air) tested periodically over an extended period of time (100 hours) in order to probe ambient operating stability (Figure 7c). The performance is maintained during initial stages (up to 10 hours), but there is a reduction in mobility, by about half, after 100 hours $\left(\sim 0.28 \mathrm{~cm}^{2} \mathrm{~V}^{-1} \mathrm{~s}^{-1}\right.$ to $\sim 0.14$ $\mathrm{cm}^{2} \mathrm{~V}^{-1} \mathrm{~s}^{-1}$ ). While $I_{\text {on }}$ was maintained, there was a sharp increase in $V_{T}$ and decrease in $I_{\text {off }}$ after 10 
hours. This potentially indicates the introduction of charge trapping states at the dielectric/OSC interface. The slight delay may reflect the time needed for air to diffuse into the device and towards the interface. While the deep LUMO level $(-4.24 \mathrm{eV})$ indicates ambient thermodynamic stability of the reduced state, a fact supported by the retention of $I_{\text {on }}$ throughout, these observations highlight that device structure and thin film quality play a crucial part in truly air stable devices, as was observed by Tian et al.. ${ }^{[36]}$ These results indicate that similar optimization of $\operatorname{diFIDT}-\operatorname{di}\left(\mathbf{C}(\mathbf{C N})_{2}\right)$ thin film morphology could enable access to truly air-stable devices.

\section{Conclusion}

In summary, we report the synthesis of two new highly electron-deficient small molecules based on the IDT core incorporating backbone fluorination on the central phenyl ring, namely diFIDT-di(O) and diFIDT-di(C(CN)2). DiFIDT-di(O) and diFIDT-di(C(CN)2) exhibit LUMO/HOMO energies of $-3.76 \mathrm{eV} /-5.96 \mathrm{eV}$ and $-4.24 \mathrm{eV} /-6.00 \mathrm{eV}$ respectively, corresponding to a depression of $0.2-0.3$ $\mathrm{eV}$ in the LUMO energy by direct comparison with the non-fluorinated analogues, IDT-di(O) and IDT-di(C(CN)2). The deep LUMO and surprisingly superior solubility of $\operatorname{diFIDT-di(C(CN)2)}$ compared to the non-fluorinated analogue enabled the fabrication of solution-processed OFET devices exhibiting high unipolar electron mobility (up to $0.49 \mathrm{~cm}^{2} \mathrm{~V}^{-1} \mathrm{~s}^{-1}$ ) via scalable blade-coating. Such devices exhibited highly promising stability under ambient conditions, with good performance maintained after $100 \mathrm{hrs.}$

As indicated by TGA and DSC analysis, fluorination of IDT-di(O) is shown to increase degradation onset and melting temperature $\left(T_{d}=360^{\circ} \mathrm{C}\right.$ vs $331^{\circ} \mathrm{C}$ and $T_{m}=224^{\circ} \mathrm{C}$ vs $\left.172^{\circ} \mathrm{C}\right)$ while a decrease is observed for fluorination of IDT-di(C(CN)2 $)\left(T_{d}=319^{\circ} \mathrm{C}\right.$ vs $349^{\circ} \mathrm{C}$ and $T_{m}=249^{\circ} \mathrm{C}$ vs $\left.>300^{\circ} \mathrm{C}\right)$. In addition, fluorination is shown to modify crystal packing considerably. DiFIDT-di(O) retains a planar slipped stack motif with improved inter-stack registry, whereas $\operatorname{diFIDT-di(C(CN)})$ adopts a tilted slipped stack motif. Computational analysis of the crystal packing suggests that the improved solubility can be attributed to backbone torsion arising from the close proximity of the fluorine to the 
dicyanomethylene group. Such results suggest that positioning of fluorine groups in the vicinity of strongly electron deficient groups may be a useful strategy to overcome detrimental solubility issues whilst maintaining the beneficial impact of fluorination on molecular energy levels.

\section{Experimental}

Diethyl 2,5-dibromo-3,6-difluoroterephthalate ([2]): To a 1.0 M solution (THF 1:1 toluene) of 2,2,6,6-tetramethylpiperidinylmagnesium chloride lithium chloride complex (100 mL, $100 \mathrm{mmol}, 2.3$ equiv) at $-40^{\circ} \mathrm{C}$ under inert atmosphere was added drop-wise a solution of 1,4-dibromo-2,5-difluorobenzene ([1]) (11.82 g, $43.48 \mathrm{mmol})$ in anhydrous THF (150 mL) over 30 minutes via syringe pump. After addition, the reaction mixture was stirred at $-40^{\circ} \mathrm{C}$ for 5 hours before ethyl chloroformate $(9.98$ $\mathrm{mL}, 104$ mmol, 2.4 equiv) was added in one go. The mixture was then allowed to warm to RT overnight. Aqueous hydrochloric acid $(1.0 \mathrm{M}, 200 \mathrm{~mL})$ was added and the mixture stirred at RT for 30 minutes. The product was extracted with diethyl ether $(3 \times 50 \mathrm{~mL})$. The combined organics were dried over anhydrous magnesium sulphate, filtered and the solvent removed in vacuo. The crude product was triturated with n-pentane to form a suspension. The product was filtered and washed with cold n-pentane then cold acetone, collected and dried under vacuum to give 2,5-dibromo-3,6-difluoroterephthalic acid diethyl ester ([2]) (5.50 g, $30 \%)$ as a cream solid. ${ }^{1} \mathrm{H}$ NMR $\left(400 \mathrm{MHz}, \mathrm{CDCl}_{3}, \delta\right)$ : $4.47\left(\mathrm{q},{ }^{3} \mathrm{~J}=7.0 \mathrm{~Hz}, 4 \mathrm{H}, \mathrm{CH}_{2}\right), 1.41\left(\mathrm{t},{ }^{3} \mathrm{~J}=7.0 \mathrm{~Hz}, 6 \mathrm{H}, \mathrm{CH}_{3}\right) .{ }^{13} \mathrm{C} \mathrm{NMR}\left(101 \mathrm{MHz}, \mathrm{CDCl}_{3}, \delta\right)$ : 161.62, $152.44\left(\mathrm{dd},{ }^{1} J=252 \mathrm{~Hz},{ }^{4} J=4.5 \mathrm{~Hz}, \mathrm{CF}\right), 127.21-126.78(\mathrm{~m}, \mathrm{CF}), 107.79-107.49(\mathrm{~m}$, CF), 63.37, 14.19. ${ }^{19} \mathrm{~F}$ NMR (377 MHz, $\left.\mathrm{CDCl}_{3}, \delta\right)-108.69$ (s, 2F, CF). HRMS (ES-TOF) m/z: $[\mathrm{M}+\mathrm{H}]^{+}$calcd for $\mathrm{C}_{12} \mathrm{H}_{10} \mathrm{O}_{4} \mathrm{~F}_{2} \mathrm{Br}_{2}, 413.8932$; found, 413.8914 .

Diethyl 2,5-difluoro-3,6-bis(5-hexylthiophen-2-yl)terephthalate ([4]): A mixture of 2,5-dibromo-3,6difluoroterephthalic acid diethyl ester $(2.2 \mathrm{~g}, 5.3 \mathrm{mmol})$, (5-hexylthiophen-2-yl)trimethylstannane ([3]) (5.5 g, $12.7 \mathrm{mmol}, 2.4$ equiv) in anhydrous DMF (40 mL) were degassed for 45 mins. Tetrakis(triphenylphosphine)palladium(0) (306 mg, $0.26 \mathrm{mmol}, 0.05$ equiv) was added and the mixture degassed for a further 15 mins. The mixture was stirred at $100^{\circ} \mathrm{C}$ for 17 hours. The mixture 
was diluted with DCM $(100 \mathrm{~mL})$ and the crude reaction mixture passed through a plug of $15 \% \mathrm{KF}$ in silica, eluting with DCM. The solvent was then concentrated in vacuo. DCM (100 mL) was added and the organic phase washed with water $(4 \times 50 \mathrm{~mL})$ and brine $(50 \mathrm{~mL})$. The combined organics were dried over anhydrous magnesium sulfate, filtered and the solvent removed in vacuo. The crude product was purified by silica gel chromatography (petroleum ether 2:1 DCM). The product was collected and dried under vacuum to give diethyl 2,5-difluoro-3,6-bis(5-hexylthiophen-2yl)terephthalate ([4]) $(2.60 \mathrm{~g}, 83 \%)$ as a pale orange solid. ${ }^{1} \mathrm{H} \mathrm{NMR}\left(400 \mathrm{MHz}, \mathrm{CDCl}_{3}, \delta\right): 7.00$ (d, $\left.\left.{ }^{3} J=3.5 \mathrm{~Hz}, 2 \mathrm{H}, \mathrm{ArH}\right)\right), 6.76\left(\mathrm{~d},{ }^{3} J=3.5 \mathrm{~Hz}, 2 \mathrm{H}, \mathrm{ArH}\right), 4.26\left(\mathrm{q},{ }^{3} J=7.2 \mathrm{~Hz}, 4 \mathrm{H}, \mathrm{CH}_{2}\right), 2.83\left(\mathrm{t},{ }^{3} J\right.$ $\left.=7.5 \mathrm{~Hz}, 4 \mathrm{H}, \mathrm{CH}_{2}\right), 1.74-1.64\left(\mathrm{~m}, 4 \mathrm{H}, \mathrm{CH}_{2}\right), 1.42-1.24\left(\mathrm{~m}, 12 \mathrm{H}, \mathrm{CH}_{2}\right), 1.18\left(\mathrm{t},{ }^{3} \mathrm{~J}=7.2 \mathrm{~Hz}, 6\right.$ $\left.\mathrm{H}, \mathrm{CH}_{3}\right), 0.89\left(\mathrm{t},{ }^{3} \mathrm{~J}=6.8 \mathrm{~Hz}, 6 \mathrm{H}, \mathrm{CH}_{3}\right) .{ }^{13} \mathrm{C} \mathrm{NMR}\left(101 \mathrm{MHz}, \mathrm{CDCl}_{3}, \delta\right): 163.94,152.06\left(\mathrm{dd},{ }^{1} J=\right.$ $\left.252 \mathrm{~Hz},{ }^{4} \mathrm{~J}=4.5 \mathrm{~Hz}, \mathrm{CF}\right), 149.40,129.44,128.43,125.16-124.79$ (m, CF), 124.47, $122.08-121.76$ (m, CF), 62.42, 31.67, 30.21, 28.90, 22.70, 14.20, 13.95. $\left.{ }^{19} \mathrm{~F} \mathrm{NMR} \mathrm{(377} \mathrm{MHz,} \mathrm{CDCl}_{3}, \delta\right):-119.94$ (s, 2F, CF). HRMS (ES-TOF) m/z: [M+H] $]^{+}$calcd for $\mathrm{C}_{32} \mathrm{H}_{41} \mathrm{O}_{4} \mathrm{~S}_{2} \mathrm{~F}_{2}, 591.2413$; found, 591.2414.

2,5-bis(5-hexylthiophen-2-yl)-3,6-difluoroterephthalic acid ([5]): Diethyl 2,5-difluoro-3,6-bis(5hexylthiophen-2-yl)terephthalate ([4]) (1.5 g, $2.54 \mathrm{mmol})$ was suspended in ethanol (30 mL). KOH (1.06 g, $19.00 \mathrm{mmol}, 7.5$ equiv) was added as a single portion. The suspension was heated to reflux overnight. Upon heating a solution followed by a suspension was observed. The reaction was cooled to $\mathrm{RT}$ and aqueous hydrochloric acid $(2.0 \mathrm{M}, 75 \mathrm{~mL})$ was added with stirring for 5 mins. The resulting precipitate was filtered, washed with plenty of water and dried in an oven at $140^{\circ} \mathrm{C}$ to give $1.32 \mathrm{~g}(98$ \%) of greenish solid ([5]). ${ }^{1} \mathrm{H}$ NMR (400 MHz, DMSO- $\left.d_{6}, \delta\right): 7.13\left(\mathrm{~d},{ }^{3} J=6.9 \mathrm{~Hz}, 2 \mathrm{H}, \mathrm{ArH}\right), 6.93$ $\left(\mathrm{d},{ }^{3} J=6.9 \mathrm{~Hz}, 2 \mathrm{H}, \mathrm{ArH}\right), 2.83\left(\mathrm{t},{ }^{3} J=7.4 \mathrm{~Hz}, 4 \mathrm{H}, \mathrm{CH}_{2}\right), 1.69-1.58\left(\mathrm{~m}, 4 \mathrm{H}, \mathrm{CH}_{2}\right), 1.41-1.21(\mathrm{~m}$, $\left.12 \mathrm{H}, \mathrm{CH}_{2}\right), 0.8\left(\mathrm{t},{ }^{3} \mathrm{~J}=7.0 \mathrm{~Hz}, 6 \mathrm{H}, \mathrm{CH}_{3}\right) .{ }^{13} \mathrm{C}$ NMR (101 MHz, DMSO-d,$\delta$ ): 164.39, 150.64 (dd, $\left.{ }^{1} J=247 \mathrm{~Hz},{ }^{4} J=2.5 \mathrm{~Hz}, \mathrm{CF}\right), 148.73,129.58,127.45,125.63-125.17(\mathrm{~m}, \mathrm{CF}), 124.98,120.21-$ 119.78 (m, CF), 30.98, 30.90, 29.20, 28.14, 22.00, 13.90. ${ }^{19}$ F NMR (377 MHz, DMSO-d6, $\left.\delta\right):-118.49$ (s, 2F, CF). HRMS (CI) m/z: [M+H] ${ }^{+}$calcd for $\mathrm{C}_{28} \mathrm{H}_{31} \mathrm{O}_{4} \mathrm{~S}_{2} \mathrm{~F}_{2}, 533.1626$; found, 533.1639. 
Difluoro-3,6-di-(5-hexylthiophen-2-yl-terephthalic acid (1.2 g, $2.24 \mathrm{mmol})$ was suspended in anhydrous DCM (25 mL) and catalytic anhydrous DMF (0.1 mL $1.12 \mathrm{mmol}, 0.5$ equiv). Thionyl chloride $(0.98 \mathrm{~mL}, 13.47 \mathrm{mmol}, 6.0$ equiv) was added dropwise over 15 minutes. The reaction heated to $50^{\circ} \mathrm{C}$ overnight. Solvent was removed to give an orange oil which was used in the next step without further purification. The acyl chloride was redissolved in anhydrous DCM $(50 \mathrm{~mL})$ and then added to a suspension of anhydrous $\mathrm{AlCl}_{3}(1.52 \mathrm{~g})$ in $\mathrm{DCM}(50 \mathrm{~mL})$ at $0^{\circ} \mathrm{C}$. The resultant mixture was allowed to warm to RT and stirred overnight. The mixture was poured into cold aqueous hydrochloric acid (2.0 M, $100 \mathrm{~mL}$ ), causing a deep blue precipitate to form which was collected by filtration. Washing with aqueous hydrochloric acid (2.0 M), water, and acetone followed by drying in vacuo afforded a cyan blue solid $(0.89 \mathrm{~g}, 80 \%) . \mathrm{mp} 221^{\circ} \mathrm{C} .{ }^{1} \mathrm{H}$ NMR $\left(400 \mathrm{MHz}, \mathrm{CDCl}_{3}, \delta\right): 6.83(\mathrm{~s}, 2 \mathrm{H}$, $\mathrm{ArH}), 2.80\left(\mathrm{t},{ }^{3} \mathrm{~J}=7.5 \mathrm{~Hz}, 4 \mathrm{H}, \mathrm{CH}_{2}\right), 1.72-1.63\left(\mathrm{~m}, 4 \mathrm{H}, \mathrm{CH}_{2}\right), 1.42-1.24\left(\mathrm{~m}, 12 \mathrm{H}, \mathrm{CH}_{2}\right), 0.90$ (t, $\left.{ }^{3} J=6.9 \mathrm{~Hz}, 6 \mathrm{H}, \mathrm{CH}_{3}\right) .{ }^{13} \mathrm{C}$ NMR $\left(101 \mathrm{MHz}, \mathrm{TCE}-d_{2}, 120^{\circ} \mathrm{C}, \delta\right): 181.33,154.16,149.26,146.14$ (dd, $\left.{ }^{1} J=265 \mathrm{~Hz},{ }^{4} J=2.9 \mathrm{~Hz}, \mathrm{CF}\right), 140.56,129.46-129.20(\mathrm{~m}, \mathrm{CF}), 127.27-127.06(\mathrm{~m}, \mathrm{CF}), 31.13$, 30.88, 30.42, 28.31, 22.12, 13.51. ${ }^{19} \mathrm{~F}$ NMR (377 MHz, $\left.\mathrm{CDCl}_{3}, \delta\right):-129.99$ (s, 2F, CF). IR $\left(\mathrm{cm}^{-1}\right)$ $1708(\mathrm{C}=\mathrm{O})$. HRMS (ES-TOF) m/z: $[\mathrm{M}+\mathrm{H}]^{+}$calcd for $\mathrm{C}_{28} \mathrm{H}_{27} \mathrm{~F}_{2} \mathrm{O}_{2} \mathrm{~S}_{2}, 497.1421$; found, 497.1415.

\section{2,2'-(5,10-difluoro-2,7-dihexyl-s-indaceno[1,2-b:5,6-b']dithiophene-4,9-diylidene)dimalononitrile}

$\left(\boldsymbol{d i F I D T}-\operatorname{di}\left(\boldsymbol{C}(\boldsymbol{C N})_{2}\right)\right): \quad$ 2,7-dihexyl-5,10-difluoro-s-indaceno[1,2-b:5,6-b']dithiophene-4,9-dione (250 mg, $0.50 \mathrm{mmol})$ and malononitrile $(317 \mathrm{mg}, 5.0 \mathrm{mmol}, 10$ equivs $)$ were dissolved in anhydrous DCM (40 mL). Pyridine (0.39 mL, $6.0 \mathrm{mmol}, 12$ equivs) was added and the mixture stirred overnight at room temperature. Aqueous hydrochloric acid $(2.0 \mathrm{M}, 40 \mathrm{~mL})$ was added and the crude product extracted with chloroform $(2 \times 50 \mathrm{~mL})$. The combined organic extracts were rinsed with water $(2 \mathrm{x}$ $50 \mathrm{~mL})$ and brine $(50 \mathrm{~mL})$, dried over anhydrous sodium sulfate, filtered and concentrated under reduced pressure. The residue was reprecipitated in the minimum amount of hot DCM with methanol, filtered, washed with methanol and dried to give a deep green solid $(239 \mathrm{mg}, 80 \%) . \mathrm{mp} 248^{\circ} \mathrm{C} ;{ }^{1} \mathrm{H}$ NMR (400 MHz, $\left.\mathrm{CDCl}_{3}, \delta\right): 7.34(\mathrm{~s}, 2 \mathrm{H}, \mathrm{ArH}), 2.84\left(\mathrm{t},{ }^{3} \mathrm{~J}=7.0 \mathrm{~Hz}, 4 \mathrm{H}, \mathrm{CH}_{2}\right), 1.72-1.65(\mathrm{~m}, 4 \mathrm{H}$, 
$\left.\mathrm{CH}_{2}\right), 1.43-1.24\left(\mathrm{~m}, 12 \mathrm{H}, \mathrm{CH}_{2}\right), 0.90\left(\mathrm{t},{ }^{3} \mathrm{~J}=7.0 \mathrm{~Hz}, 6 \mathrm{H}, \mathrm{CH}_{3}\right) .{ }^{13} \mathrm{C} \mathrm{NMR}\left(101 \mathrm{MHz}, \mathrm{CDCl}_{3}, 50{ }^{\circ} \mathrm{C}\right.$, $\delta): 155.27,152.64,149.40\left(\mathrm{dd},{ }^{1} J=265 \mathrm{~Hz},{ }^{4} J=2.5 \mathrm{~Hz}, \mathrm{CF}\right), 144.68,139.65,127.86-127.54(\mathrm{~m}$, CF), 127.36 - 127.07 (m, CF), 120.46, 113.53, 112.34, 82.07, 31.58, 31.40, 31.08, 28.77, 22.65, 14.10. ${ }^{19} \mathrm{~F}$ NMR $\left(377 \mathrm{MHz}, \mathrm{CDCl}_{3}, \delta\right):-108.18(\mathrm{~s}, 2 \mathrm{~F}, \mathrm{CF}) . \mathrm{IR}\left(\mathrm{cm}^{-1}\right) 2226(\mathrm{C} \equiv \mathrm{N})$. HRMS (ES-TOF) $\mathrm{m} / \mathrm{z}$ : [M] ${ }^{-}$calcd for $\mathrm{C}_{34} \mathrm{H}_{28} \mathrm{~F}_{2} \mathrm{~N}_{4} \mathrm{~S}_{2}, 594.1723$; found, 594.1711.

Solubility Testing: To a $6 \mathrm{~mL}$ glass vial containing a small stirrer bar and $1.00 \pm 0.02 \mathrm{mg}$ of IDT$\operatorname{di}\left(\mathbf{C}(\mathbf{C N})_{2}\right) / \mathbf{d i F I D T}-\operatorname{di}\left(\mathbf{C}(\mathbf{C N})_{2}\right)$ was added $0.1 \mathrm{~mL}$ chlorobenzene via a micropipette. The mixture was then stirred (400 rpm) at $25^{\circ} \mathrm{C}$ for 20 minutes. If solid remained, more solvent was added and the process repeated until complete dissolution. The testing was repeated 3 times for each compound to assure reproducibility.

DFT Calculations: DFT/TD-DFT calculations were carried out using the B3LYP hybrid functional and the 6-311+G(d,p) basis set in the GAUSSIAN09 software package. Alkyl chains were replaced with a methyl group to simplify calculations and reduce computational time. Structures were optimized, and a frequency analysis was performed. Transfer Integrals: Electron transfer integrals (LUMO:LUMO overlap, B3LYP/6-31G(d)) for molecular pairs from crystal structures of IDT$\operatorname{di}(\mathbf{C}(\mathbf{C N}))_{2}$ and diFIDT-di(C(CN) $)_{2}$ were calculated using the approach of Valeev et al with Gaussian 16 Rev A.03 software. ${ }^{[50]}$ Symmetry Adapted Perturbation Theory (SAPTO) calculations: Symmetry adapted perturbation interaction energies (SAPT0/jun-cc-pvdz) were calculated for molecular pairs from crystal structures using Psi4 software. In each case, H and F atoms were first allowed to relax geometrically to allow for error in positioning hydrogen atoms from x-ray diffraction data, and to allow the in silico substitution of $\mathrm{H}$ and $\mathrm{F}$ atoms. Total SAPT0 energies (TOT) are decomposed into electrostatic (ES, Keesom interaction), exchange (EX, Pauli repulsion), induction (IND, Debye interaction) and dispersion (DISP, London interaction) energies. All energies are in $\mathrm{kcal} / \mathrm{mol}$. 
Characterization: ${ }^{1} \mathrm{H},{ }^{19} \mathrm{~F}$, and ${ }^{13} \mathrm{C}$ NMR spectra were recorded on a Bruker AV-400 (400 MHz), using the residual solvent resonance of chloroform-d, DMSO- $\mathrm{d}_{6}$ or 1,1,2,2-tetrachloroethane- $\mathrm{d}_{2}$ and are given in ppm. Electrospray and chemical ionization mass spectrometry were performed with a Waters LCT Premier (ES-ToF) and a Micromass Autospec Premier mass spectrometer respectively. UV-vis spectra were recorded on a UV-1800 Shimadzu UV-vis spectrometer. TGA measurements, using $\geq 2 \mathrm{mg}$ of material, were conducted under nitrogen between 25 and $600{ }^{\circ} \mathrm{C}$ at a scan rate of 10 K/min with a Mettler Toledo TGA/DSC 1LF/UMX instrument. DSC measurements, using 3 mg of material, were conducted under nitrogen at scan rate of $10{ }^{\circ} \mathrm{C} \mathrm{min}^{-1}$ with a TA DSC-Q20 instrument. The melting temperature $\left(T_{m}\right)$ for $\operatorname{diFIDT-di(O)}$ and $\operatorname{diFIDT-di}\left(\mathbf{C}(\mathbf{C N})_{2}\right)$ were extracted from the DSC data as the extrapolated onset temperature of the major endotherm of the $1^{\text {st }}$ heating cycle.

Single Crystal Growth and Analysis: Small molecule solutions in chloroform (diFIDT-di(O)) or chlorobenzene (diFIDT-di(C(CN)2)) $(0.5 \mathrm{mg}$ in $0.75 \mathrm{~mL})$ were placed in $2 \mathrm{~mL}$ glass vials. These vials were placed into a larger vial containing methanol $(2.5 \mathrm{~mL})$ which was then sealed. Equilibration via vapour diffusion occurred over 3-5 d after which crystals were analysed. Details of the structural determinations can be found in the Supporting Information.

Device Fabrication and Characterization: All film preparation and characterization steps were carried out under inert atmosphere. Organic thin film transistors (OTFTs) were fabricated in bottomcontact top-gate (BC-TG) configuration. Spin-coated Devices: Gold source-drain electrodes of $40 \mathrm{~nm}$ were deposited via thermal evaporation in high vacuum $\left(10^{-6} \mathrm{mbar}\right)$ resulting in channel lengths in the range of $30-100 \mu \mathrm{m}$ and width $1 \mathrm{~mm}$. Prior to semiconductor deposition both source-drain substrate and solution were heated at $100^{\circ} \mathrm{C}$. The small molecule solution $(5 \mathrm{mg} / \mathrm{ml}$ in chlorobenzene) was spin coated with spin speed of $2000 \mathrm{rpm}$ for $30 \mathrm{sec}$ and then annealed at various temperatures for 15 minutes. $900 \mathrm{~nm}$ of CYTOP were used as the dielectric layer followed by $40 \mathrm{~nm}$ of thermal evaporated aluminum which formed the gate electrode. Device fabrication and electrical measurements were performed in a nitrogen glovebox. Transistor characterization was carried out 
using an Agilent B2902 semiconductor parameter analyzer. Mobility was extracted from the slope of $\sqrt{I_{D}}$ versus $V_{G}$. Blade-coated Devices: The $\mathrm{Al} / \mathrm{Au}(5 \mathrm{~nm} / 35 \mathrm{~nm})$ source and drain electrodes were vapour-deposited using shadow mask on the glass substrate. The small molecule solution $(5 \mathrm{mg} / \mathrm{ml}$ in chlorobenzene) was blade coated on the substrates at $100^{\circ} \mathrm{C}$ with the blade speed of $50 \mathrm{~mm} / \mathrm{s}$ and then the substrates were kept at $100^{\circ} \mathrm{C}$ for 5 mins. $~ 900 \mathrm{~nm}$ CYTOP film was deposited on top of the semiconductor by spin coating at $2000 \mathrm{rpm}$ spin rate followed by annealing at $50^{\circ} \mathrm{C}$ for $1 \mathrm{hr}$. The capacitance of the CYTOP dielectric was measured $2.1 \mathrm{nF} / \mathrm{cm}^{2} .70 \mathrm{~nm} \mathrm{Al} \mathrm{was} \mathrm{vapour-deposited} \mathrm{at}$ the top as the gate electrode. The current-voltage characteristics for the devices were measured using KEYSIGHT B2912A Precision Source/Measure Unit. Air Stability Tests: A series of spin-coated devices fabricated in $\mathrm{N}_{2}$ (as above) were exposed to air for over 100 hours and the electrical characteristics were measured using an Agilent B2920A semiconductor parameter analyser.

\section{Supporting Information}

Supporting Information is available from the Wiley Online Library or from the author.

\section{Acknowledgements}

We thank the Engineering and Physical Sciences Research Council (EPSRC) (grant EP/L016702/1) and the Royal Society and the Wolfson Foundation (for Royal Society Wolfson Fellowship) for support. A.B. and T.D.A., are grateful to KAUST for the financial support

Received: ((will be filled in by the editorial staff))

Revised: ((will be filled in by the editorial staff)) Published online: ((will be filled in by the editorial staff))

\section{References}

[1] H. Jia, T. Lei, J. Mater. Chem. C 2019, 7, 12809.

[2] S. Ahmad, J. Polym. Eng. 2014, 34, 279.

[3] J. Chen, K. Yang, X. Zhou, X. Guo, Chem. - An Asian J. 2018, 13, 2587.

[4] Z. Liu, G. Zhang, D. Zhang, Acc. Chem. Res. 2018, 51, 1422.

[5] W. Zhang, J. Smith, S. E. Watkins, R. Gysel, M. McGehee, A. Salleo, J. Kirkpatrick, S. Ashraf, T. Anthopoulos, M. Heeney, I. McCulloch, J. Am. Chem. Soc. 2010, 132, 11437.

[6] J. Kirkpatrick, C. B. Nielsen, W. Zhang, H. Bronstein, R. S. Ashraf, M. Heeney, I. 
McCulloch, Adv. Energy Mater. 2012, 2, 260.

[7] C. Liang, H. Wang, Org. Electron. 2017, 50, 443.

[8] D. Venkateshvaran, M. Nikolka, A. Sadhanala, V. Lemaur, M. Zelazny, M. Kepa, M.

Hurhangee, A. J. Kronemeijer, V. Pecunia, I. Nasrallah, I. Romanov, K. Broch, I.

McCulloch, D. Emin, Y. Olivier, J. Cornil, D. Beljonne, H. Sirringhaus, Nature 2014, 515, 384.

[9] X. Zhang, H. Bronstein, A. J. Kronemeijer, J. Smith, Y. Kim, R. J. Kline, L. J. Richter, T. D. Anthopoulos, H. Sirringhaus, K. Song, M. Heeney, W. Zhang, I. McCulloch, D. M. DeLongchamp, Nat. Commun. 2013, 4, 2238.

[10] W. Zhang, Y. Han, X. Zhu, Z. Fei, Y. Feng, N. D. Treat, H. Faber, N. Stingelin, I. Mcculloch, T. D. Anthopoulos, M. Heeney, Adv. Mater. 2015, 3922.

[11] J. T. E. Quinn, J. Zhu, X. Li, J. Wang, Y. Li, J. Mater. Chem. C 2017, 5, 8654.

[12] Y. Wang, T. Michinobu, J. Mater. Chem. C 2018, 6, 10390.

[13] O. Inganäs, Adv. Mater. 2018, 30, 1800388.

[14] W. Cao, J. Xue, Energy Environ. Sci. 2014, 7, 2123.

[15] H. Klauk, U. Zschieschang, J. Pflaum, M. Halik, Nature 2007, 445, 745.

[16] H. Usta, A. Facchetti, T. J. Marks, Acc. Chem. Res. 2011, 44, 501.

[17] R. Di Pietro, D. Fazzi, T. B. Kehoe, H. Sirringhaus, J. Am. Chem. Soc. 2012, 134, 14877.

[18] J. Dhar, U. Salzner, S. Patil, J. Mater. Chem. C 2017, 5, 7404.

[19] B. A. Jones, A. Facchetti, M. R. Wasielewski, T. J. Marks, J. Am. Chem. Soc. 2007, 129, 15259.

[20] A. Naibi Lakshminarayana, A. Ong, C. Chi, J. Mater. Chem. C 2018, 6, 3551.

[21] Q. Zhang, M. A. Kelly, N. Bauer, W. You, Acc. Chem. Res. 2017, 50, 2401.

[22] M. Kim, S. U. Ryu, S. A. Park, K. Choi, T. Kim, D. Chung, T. Park, Adv. Funct. Mater. 2019, 1904545.

[23] Y. Gao, Y. Deng, H. Tian, J. Zhang, D. Yan, Y. Geng, F. Wang, Adv. Mater. 2017, 1606217. 
[24] F. Wang, Y. Dai, W. Wang, H. Lu, L. Qiu, Y. Ding, G. Zhang, Chem. Mater. 2018, 30, 5451.

[25] D. Deng, Y. Zhang, J. Zhang, Z. Wang, L. Zhu, J. Fang, B. Xia, Z. Wang, K. Lu, W. Ma, Z. Wei, Nat. Commun. 2016, 7, 13740.

[26] H. Medlej, A. Nourdine, H. Awada, M. Abbas, C. Dagron-Lartigau, G. Wantz, L. Flandin, Eur. Polym. J. 2014, 59, 25.

[27] K. Thorley, I. McCulloch, J. Mater. Chem. C 2018, 6, 12413.

[28] H. Huang, L. Yang, A. Facchetti, T. J. Marks, Chem. Rev. 2017, 117, 10291.

[29] W. Zhao, S. Li, H. Yao, S. Zhang, Y. Zhang, B. Yang, J. Hou, J. Am. Chem. Soc. 2017, 139, 7148.

[30] D. J. Crouch, P. J. Skabara, M. Heeney, I. McCulloch, S. J. Coles, M. B. Hursthouse, Chem. Commun. 2005, 1465.

[31] Y. Li, M. Gu, Z. Pan, B. Zhang, X. Yang, J. Gu, Y. Chen, J. Mater. Chem. A 2017, 5, 10798.

[32] A. Wadsworth, M. Moser, A. Marks, M. S. Little, N. Gasparini, C. J. Brabec, D. Baran, I. McCulloch, Chem. Soc. Rev. 2019, 48, 1596.

[33] X. Song, N. Gasparini, M. M. Nahid, H. Chen, S. M. Macphee, W. Zhang, V. Norman, C. Zhu, D. Bryant, H. Ade, I. McCulloch, D. Baran, Adv. Funct. Mater. 2018, 28, 1802895.

[34] H. Bristow, K. J. Thorley, A. J. P. White, A. Wadsworth, M. Babics, Z. Hamid, W. Zhang, A. F. Paterson, J. Kosco, J. Panidi, T. D. Anthopoulos, I. McCulloch, Adv. Electron. Mater. 2019, 5, 1900344.

[35] C. Zhao, Y. Zhang, M. K. Ng, J. Org. Chem. 2007, 72, 6364.

[36] H. Tian, Y. Deng, F. Pan, L. Huang, D. Yan, Y. Geng, F. Wang, J. Mater. Chem. 2010, 20, 7998.

[37] J. D. Peltier, B. Heinrich, B. Donnio, J. Rault-Berthelot, E. Jacques, C. Poriel, ACS Appl. Mater. Interfaces 2017, 9, 8219.

[38] M. D’Lavari, W. Mitchell, C. Wang, D. Sparrow (Merck Chemicals Ltd), WO2015154845A1, 2015. 
[39] K. Feng, X. Zhang, Z. Wu, Y. Shi, M. Su, K. Yang, Y. Wang, H. Sun, J. Min, Y. Zhang, X. Cheng, H. Y. Woo, X. Guo, ACS Appl. Mater. Interfaces 2019, 11, 35924.

[40] P. Boufflet, Y. Han, Z. Fei, N. D. Treat, R. Li, D.-M. Smilgies, N. Stingelin, T. D. Anthopoulos, M. Heeney, Adv. Funct. Mater. 2015, 15, 7038.

[41] K. Kawashima, T. Fukuhara, Y. Suda, Y. Suzuki, T. Koganezawa, H. Yoshida, H. Ohkita, I. Osaka, K. Takimiya, J. Am. Chem. Soc. 2016, 138, 10265.

[42] J. H. Yun, S. Park, J. H. Heo, H. S. Lee, S. Yoon, J. Kang, S. H. Im, H. Kim, W. Lee, B. Kim, M. J. Ko, D. S. Chung, H. J. Son, Chem. Sci. 2016, 7, 6649.

[43] T. Kharandiuk, E. J. Hussien, J. Cameron, R. Petrina, N. J. Findlay, R. Naumov, W. T. Klooster, S. J. Coles, Q. Ai, S. Goodlett, C. Risko, P. J. Skabara, Chem. Mater. 2019, 31, 7070.

[44] S. K. Park, J. H. Kim, S. Y. Park, Adv. Mater. 2018, 30, 1704759.

[45] A. Y. Sosorev, Phys. Chem. Chem. Phys. 2017, 19, 25478.

[46] M. Nakano, I. Osaka, D. Hashizume, K. Takimiya, Chem. Mater. 2015, 27, 6418.

[47] E. M. Espinoza, J. A. Clark, J. Soliman, J. B. Derr, M. Morales, V. I. Vullev, J. Electrochem. Soc. 2019, 166, H3175.

[48] G. Ji, W. Zhao, J. Wei, L. Yan, Y. Han, Q. Luo, S. Yang, J. Hou, C. Q. Ma, J. Mater. Chem. A 2019, 7, 212.

[49] E. F. Valeev, V. Coropceanu, D. A. Da Silva Filho, S. Salman, J. L. Brédas, J. Am. Chem. Soc. 2006, 128, 9882 . 
$\mathbf{a}$
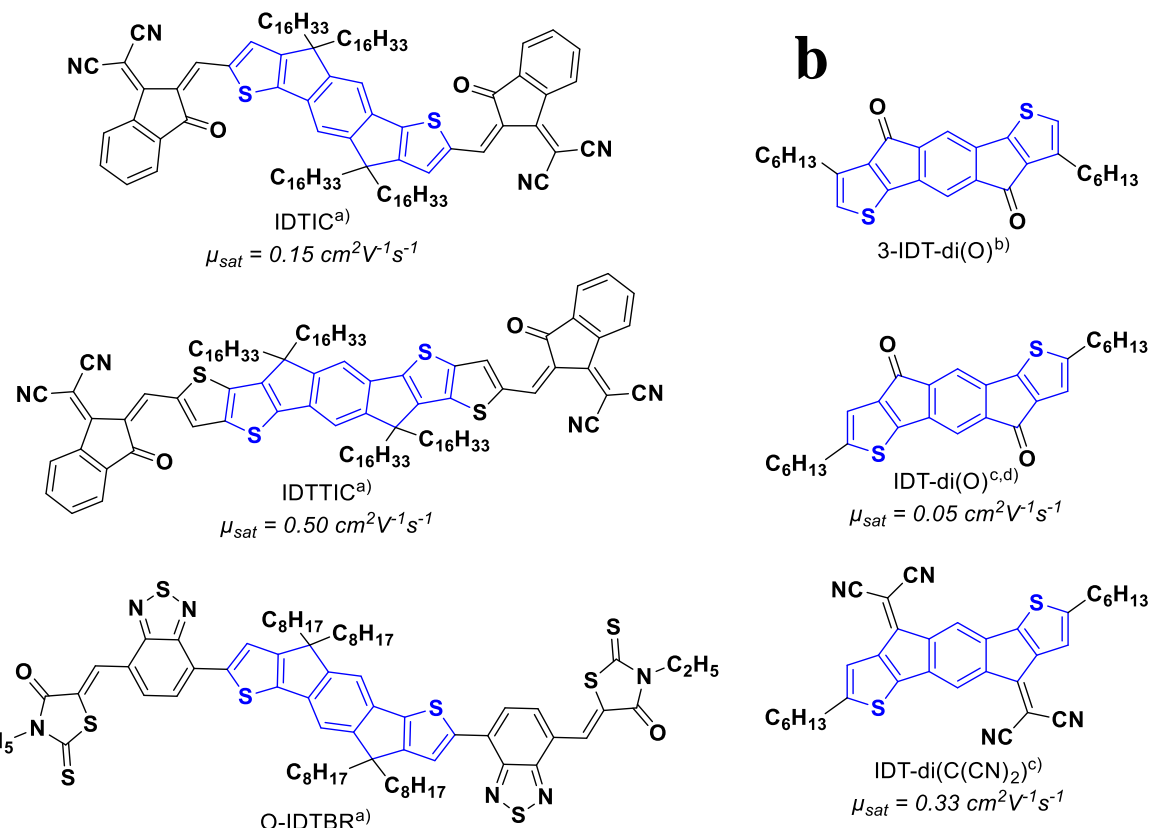

c
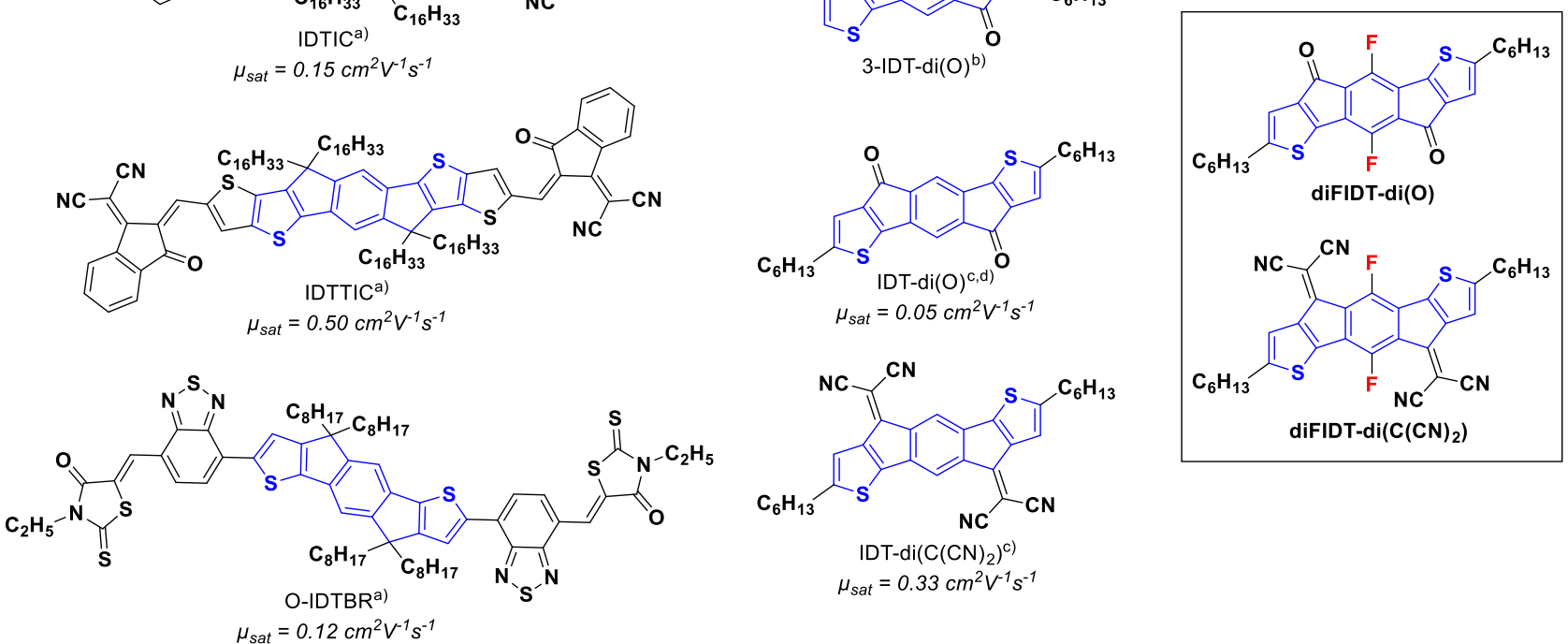

$\mu_{\text {sat }}=0.33 \mathrm{~cm}^{2} \mathrm{~V}^{-1} \mathrm{~s}^{-1}$

Figure 1. Chemical structures of previously reported n-type IDT-based small molecules for OFETs.

a) end-modified IDT. b) bridge-modified IDT. c) This work $\operatorname{diFIDT-di(O)}$ and $\operatorname{diFIDT-di(C(CN)2).~}$

${ }^{\text {a) }}$ Solution-processed, ${ }^{\text {b) }}$ mobility not reported, ${ }^{\text {c) }}$ vacuum-processed, ${ }^{\text {d) }}$ hole mobility.
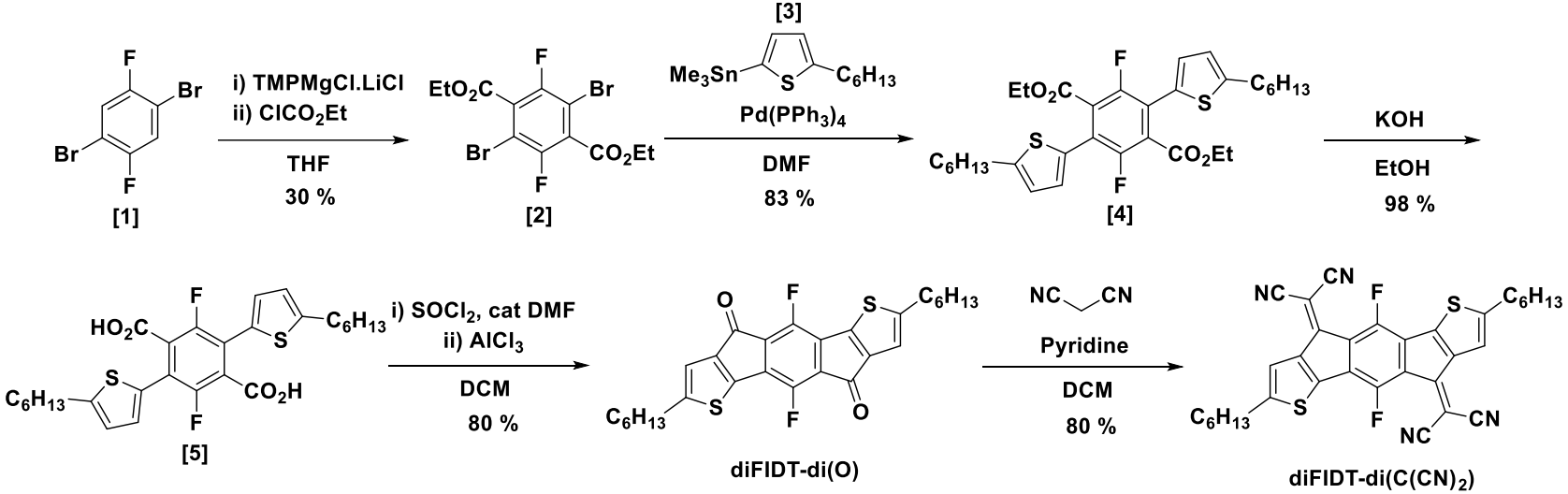

Scheme 1. Synthesis of diFIDT-di(O) and diFIDT-di(C(CN)2). 

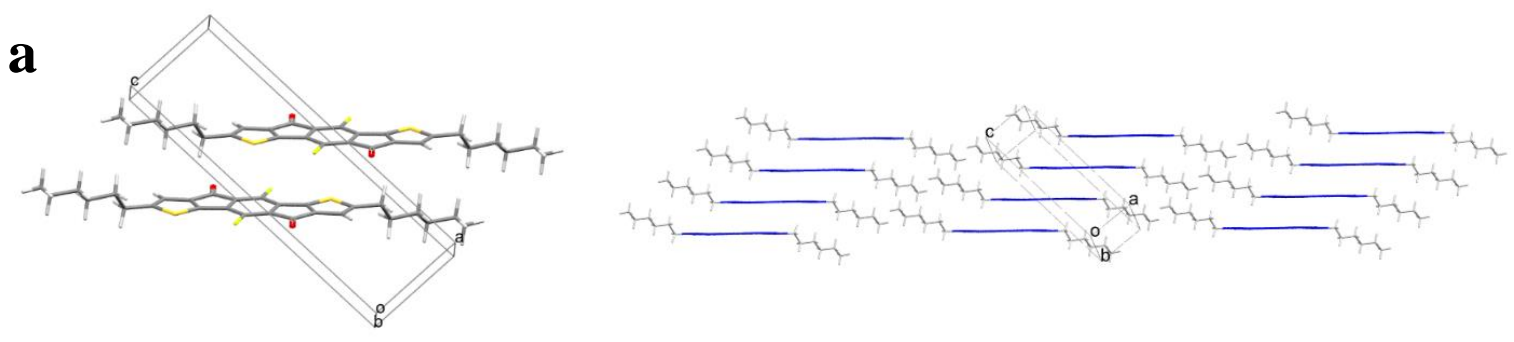

b

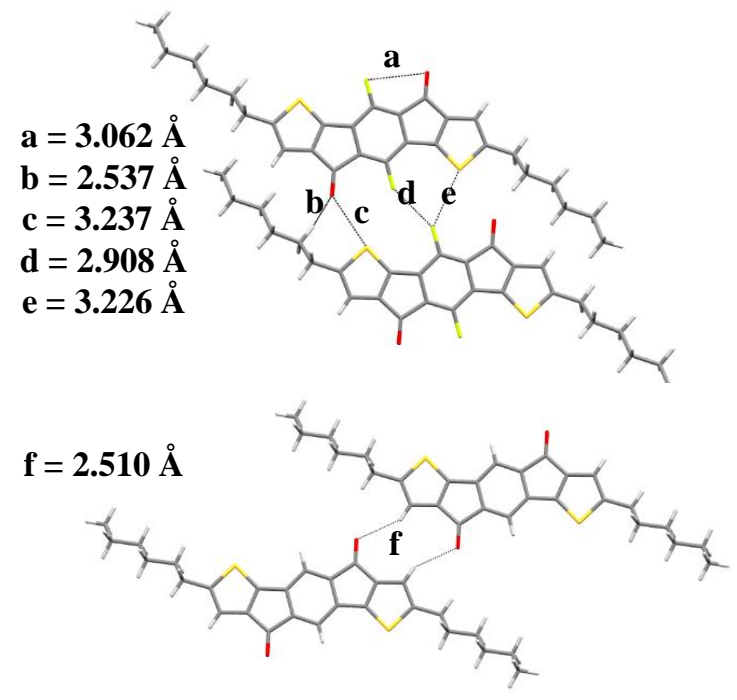

c

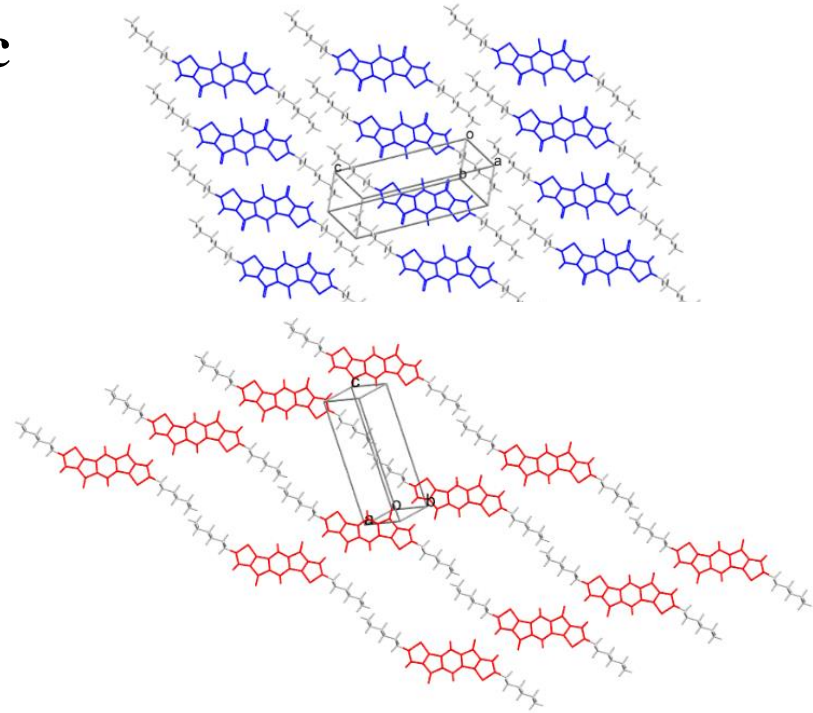

Figure 2. a) Unit cell (left) and $4 \times 3$ packing motif (right) of diFIDT-di(O). b) Inter- and intramolecular short contacts for diFIDT-di(O) (top) and IDT-di(O) (bottom). c) Interchain registry and alkyl chain interdigitation of $\mathbf{d i F I D T - d i ( O ) ~ ( t o p ) ~ a n d ~ I D T - d i ( O ) ~ ( b o t t o m ) . ~}$

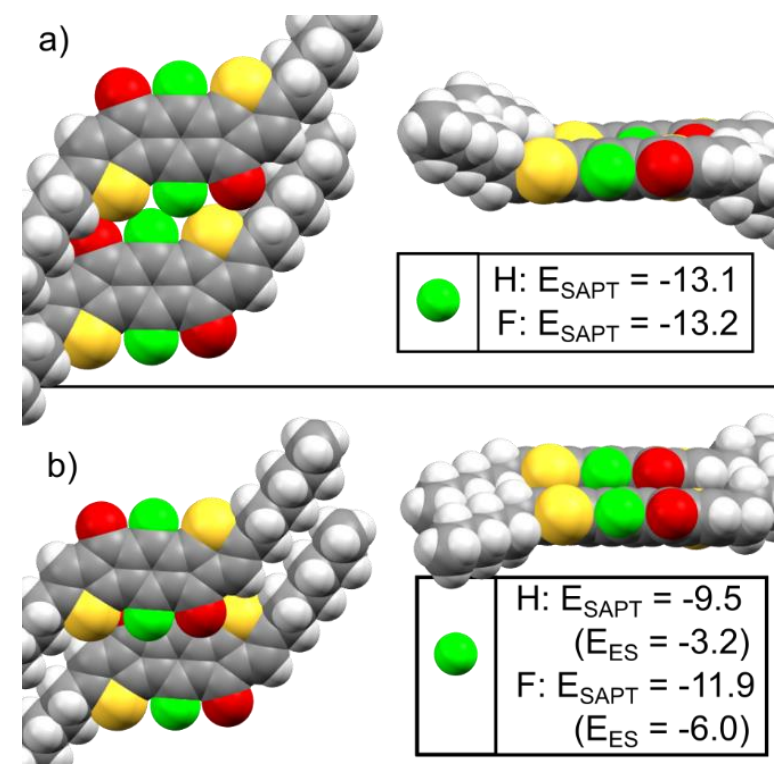

Figure 3. a) in-plane longitudinal interaction and b) edge $\pi$ stacked interaction in diFIDT-di(O) crystal packing. Total SAPT energies (ESAPT) and electrostatic energies (EES) are given for diFIDT- 
$\operatorname{di}(\mathbf{O})$ and the hypothetical IDT-di(O) molecules for the same molecular alignments. All energies in $\mathrm{kcal} / \mathrm{mol}$. Atom colors: yellow $=$ sulfur, green $=$ hydrogen or fluorine, red $=$ oxygen .

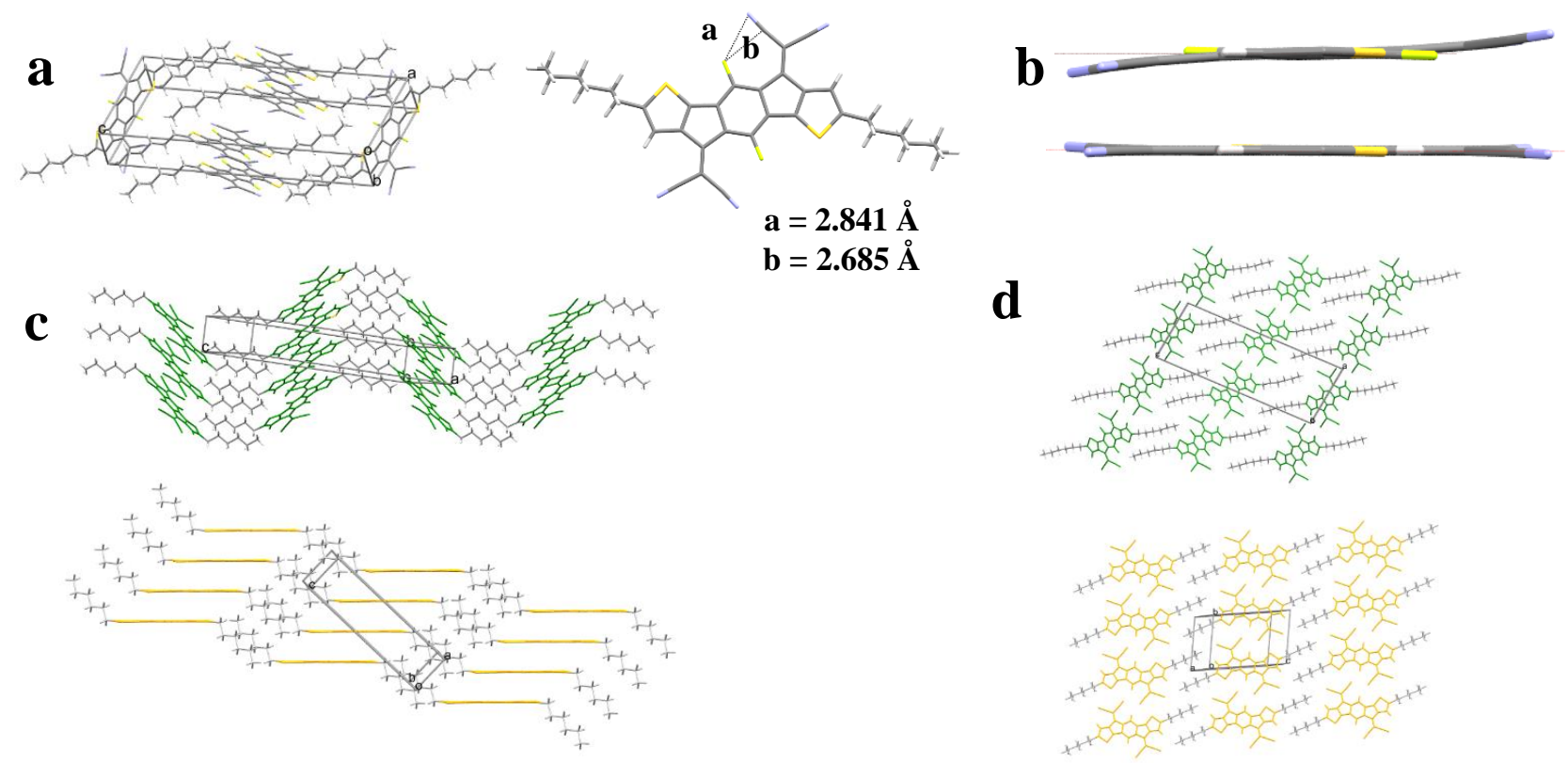

Figure 4. a) Unit cell (left) and intramolecular short contacts (right) of $\operatorname{diFIDT-di(}\left(\mathbf{C}(\mathbf{C N})_{2}\right)$. b) Dicyanomethylene torsion in $\operatorname{diFIDT-di(C(CN)2)}$ (top) versus IDT-di(C(CN)2) (bottom), viewed along the molecular long axis. c) Tilted slipped stacking of $\operatorname{diFIDT-di(C(CN)2)}$ (top) versus planar slipped stacking of IDT-di(C(CN)2) (bottom). d) Interchain registry and alkyl chain interdigitation of diFIDT-di(C(CN)2) (top) and IDT-di(C(CN)2) (bottom).

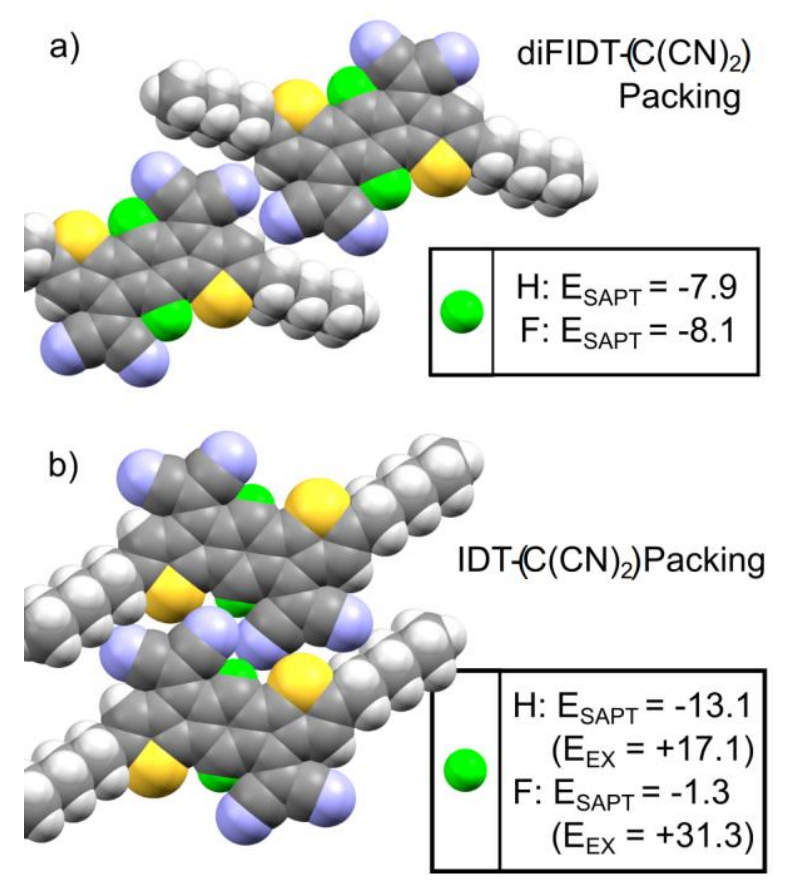


Figure 5. In-plane longitudinal interaction in a) diFIDT-di(C(CN)2) crystal packing and b) IDT$\operatorname{di}\left(\mathbf{C}(\mathbf{C N})_{2}\right)$ crystal packing. Total SAPT energies $\left(\mathrm{E}_{\mathrm{SAPT}}\right)$ and repulsive exchange energies $\left(\mathrm{E}_{\mathrm{EX}}\right)$ are given for IDT-di(C(CN) $)_{2}$ and $\operatorname{diFIDT-di(}\left(\mathbf{C}(\mathbf{C N})_{2}\right)$ molecules in each packing motif. All energies in $\mathrm{kcal} / \mathrm{mol}$. Atom colors: yellow $=$ sulfur, green $=$ hydrogen or fluorine, blue $=$ nitrogen .
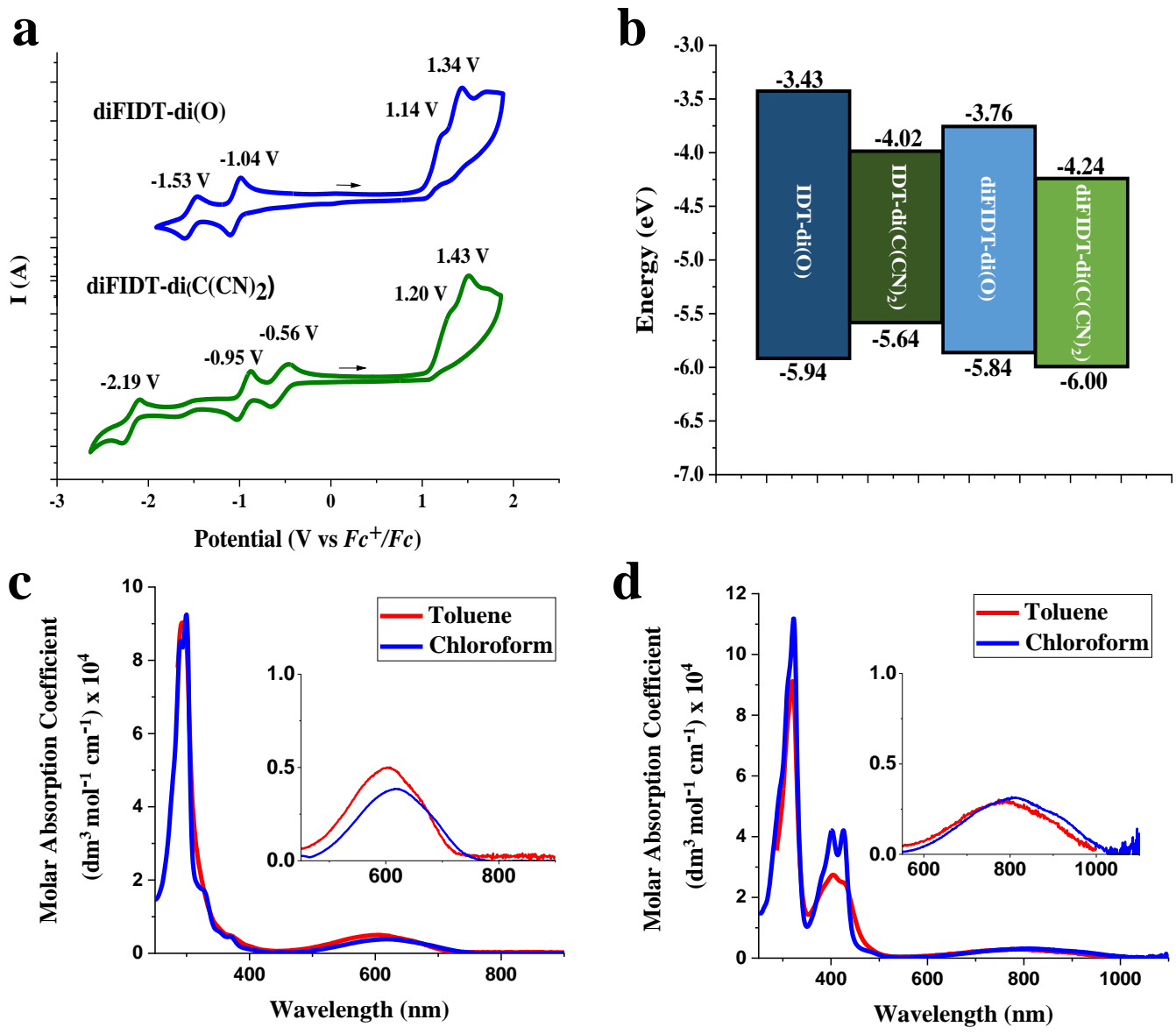

Figure 6. a) Cyclic voltammagrams of diFIDT-di(O) (top) and diFIDT-di(C(CN))2 (bottom), showing corresponding $\mathrm{E}^{1 / 2}$ or i potentials. b) Energy level schematic diagram comparing diFIDT$\operatorname{di}(\mathbf{O})$ and diFIDT-di $(\mathbf{C}(\mathbf{C N}))_{2}$ to the non-fluorinated analogues (values extracted from CV measurements). c) and d) Solution absorption spectra for c) diFIDT-di(O) and d) diFIDT$\operatorname{di}(\mathbf{C}(\mathbf{C N}))_{2}$, in chloroform and toluene. 

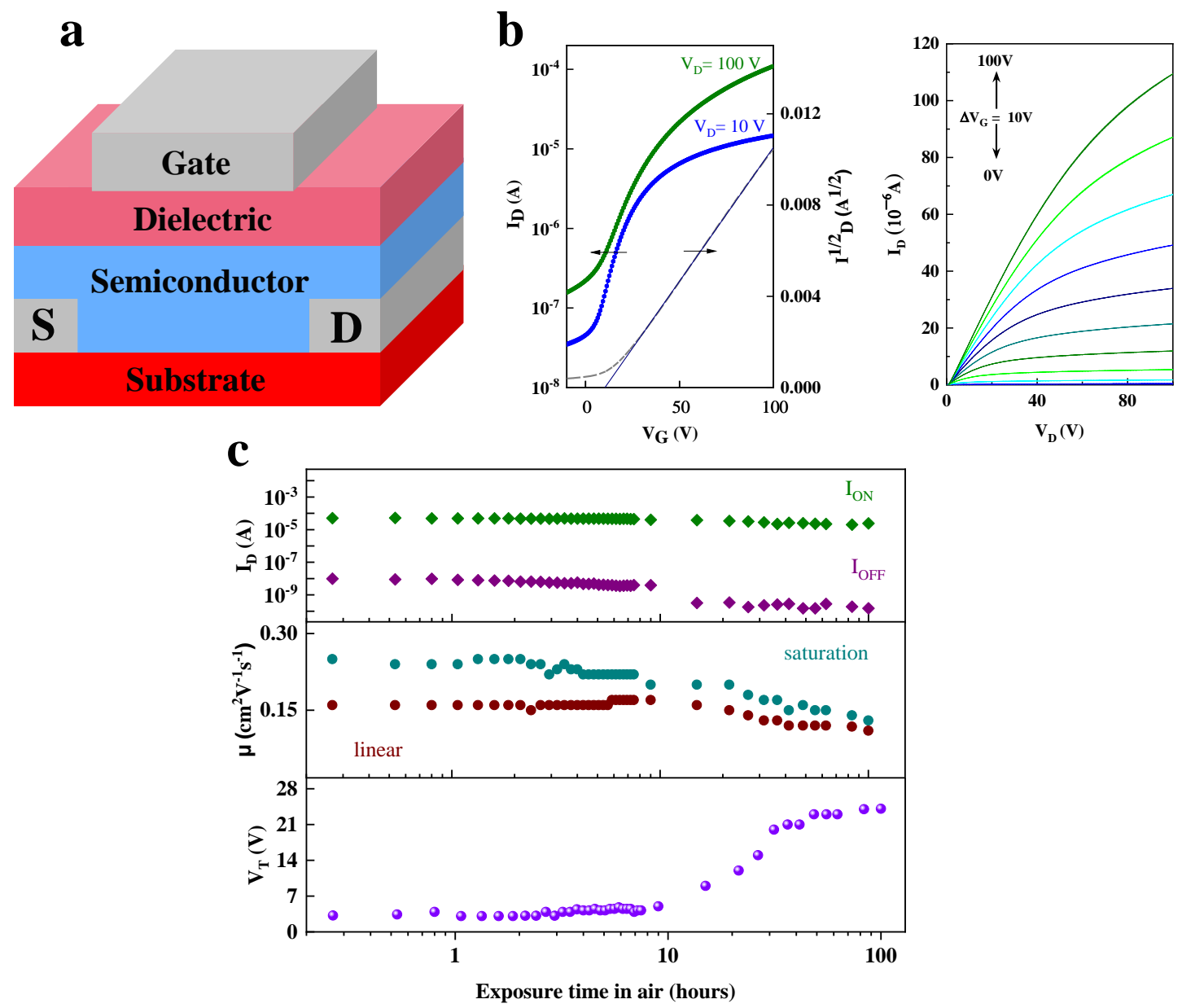

Figure 7. a) OFET device architecture, where S/D are source/drain electrodes b) Transfer (left) and output (right) curves for spin-coated BC-TG devices, post-annealed at $100^{\circ} \mathrm{C}$ and tested in $\mathrm{N}_{2}$. c) Stacked plot showing the OFET performance of spin-coated $\operatorname{diFIDT-di}\left(\mathbf{C}(\mathbf{C N})_{2}\right)$ tested in air over 100 hours. 
Table 1: Summary of material properties of diFIDT-di(O) and diFIDT-di(C(CN))2 compared to the non-fluorinated analogues. ${ }^{\text {a) }}$ extracted from CV measurements, ${ }^{\text {b) }}$ All data taken from Peltier et al. ${ }^{[37]},{ }^{c}$ in cyclohexane, ${ }^{\mathrm{d}}$ in $\mathrm{THF},{ }^{\mathrm{e}}$ in chloroform, ${ }^{\mathrm{f}}$ in toluene, ${ }^{\mathrm{g})}$ no melt observed.

\begin{tabular}{|c|c|c|c|c|c|c|}
\hline \multirow{2}{*}{ OSC } & $H O M O^{a)}$ & $L U M O^{a)}$ & $\lambda_{\max }($ solution $)$ & $T_{d}$ & $T_{m}$ & $\Delta H_{m}$ \\
\hline & {$[\mathrm{eV}]$} & {$[\mathrm{eV}]$} & {$[\mathrm{nm}]$} & {$\left[{ }^{\circ} \mathrm{C}\right]$} & {$\left[{ }^{\circ} \mathrm{C}\right]$} & {$\left[\mathrm{Jg}^{-1}\right]$} \\
\hline IDT-di(O) $)^{\mathbf{b})}$ & -5.94 & -3.43 & $579,296^{\mathrm{c})}$ & 331 & 172 & 66 \\
\hline IDT-di $\left(\mathbf{C}(\mathbf{C N})_{2}\right)^{\mathbf{b})}$ & -5.64 & -4.02 & $743,332^{\mathrm{d})}$ & 349 & $-g)$ & -g) \\
\hline diFIDT-di(O) & -5.84 & -3.76 & $617,300,290^{\mathrm{e})}$ & 360 & 221 & 83 \\
\hline \multirow{3}{*}{$\operatorname{diFIDT}-\operatorname{di}\left(\mathrm{C}(\mathrm{CN})_{2}\right)$} & \multirow{3}{*}{-6.00} & \multirow{3}{*}{-4.24} & $598,293^{\mathrm{f})}$ & \multirow{3}{*}{319} & \multirow{3}{*}{248} & \multirow{3}{*}{59} \\
\hline & & & $814,426,402,322^{\mathrm{e})}$ & & & \\
\hline & & & $779,405,320^{\mathrm{f})}$ & & & \\
\hline
\end{tabular}

Table 2. Summary of Average OFET device performance for $\left.\operatorname{diFIDT-di(} \mathbf{C}(\mathbf{C N})_{2}\right)$ in bottom contacttop gate contact configuration, annealed at $100^{\circ} \mathrm{C}$ (best values in brackets)

\begin{tabular}{ccccc}
\hline \multirow{2}{*}{$\begin{array}{c}\text { Deposition } \\
\text { Technique }\end{array}$} & $V_{T}$ & $\mu_{\text {linear }}$ & $\mu_{\text {saturated }}$ & $I_{\text {on }} / I_{\text {off }}$ \\
\cline { 2 - 5 } & {$[\mathrm{V}]$} & {$\left[\mathrm{cm}^{2} \mathrm{~V}^{-1} \mathrm{~s}^{-1}\right]$} & {$\left[\mathrm{cm}^{2} \mathrm{~V}^{-1} \mathrm{~s}^{-1}\right]$} & \\
\hline Spin-coated & 8.16 & 0.12 & $0.33(0.33)$ & $10^{2}$ \\
Blade-coated & 12.37 & 0.01 & $0.34(0.49)$ & $10^{2}-10^{3}$ \\
\hline
\end{tabular}


